\title{
MiR-182-5p and its target HOXA9 in non- small cell lung cancer: a clinical and in- silico exploration with the combination of RT-qPCR, miRNA-seq and miRNA-chip
}

Li Gao ${ }^{1 \dagger}$, Shi-bai Yan ${ }^{2 \dagger}$, Jie Yang ${ }^{3}$, Jin-liang Kong ${ }^{4}, K^{\prime}$ Shi', Fu-chao Ma², Lin-zhen Huang ${ }^{1}$, Jie Luo ${ }^{5}$, Shu-ya Yin ${ }^{1}$, Rong-quan $\mathrm{He}^{2}$, Xiao-hua $\mathrm{Hu}^{2^{*+}}$ and Gang Chen ${ }^{1 * \dagger}$

\begin{abstract}
Background: MiR-182-5p, a cancer-related microRNA (miRNA), modulates tumorigenesis and patient outcomes in various human malignances. This study interroted the clinicopathological significance and molecular mechanisms of miR-182-5p in non-small cell lung cancer (NSCLC).

Methods: The clinical significance of miR-182-5p in NSCLC subtypes was determined based on an analysis of 124 samples (lung adenocarcinomas [LUADs], $n=101$; lung squamous cell carcinomas [LUSCs], $n=23$ ) obtained from NSCLC patients and paired noncancer tissues and an analysis of data obtained from public miRNA-seq database, miRNA-chip database, and the scientific literature. The NSCLC samples $(n=124)$ were analyzed using the real-time quantitative polymerase chain reaction (RT-qPCR). Potential targets of miR-182-5p were identified using lists generated by miRWalk v.2.0, a comprehensive atlas of predicted and validated targets of miRNA-target interactions. Molecular events of miR-182-5p in NSCLC were unveiled based on a functional analysis of candidate targets. The association of miR-182-5p with one of the candidate target genes, homeobox A9 (HOXA9), was validated using inhouse RT-qPCR and dual-luciferase reporter assays.

Results: The results of the in-house RT-qPCR assays analysis of data obtained from public miRNA-seq databases, miRNA-chip databases, and the scientific literature all supported upregulation of the expression level of miR-182-5p level in NSCLC. Moreover, the in-house RT-qPCR data supported the influence of upregulated miR-182-5p on malignant progression of NSCLC. In total, 774 prospective targets of miR-182-5p were identified. These targets were mainly clustered in pathways associated with biological processes, such as axonogenesis, axonal development, and Ras protein signal transduction, as well as pathways involved in axonal guidance, melanogenesis, and longevity regulation, in multiple species. Correlation analysis of the in-house RT-qPCR data and dual-luciferase reporter assays confirmed that HOXA9 was a direct target of miR-182-5p in NSCLC.
\end{abstract}

Conclusions: The miR-182-5p expression level was upregulated in NSCLC tissues. MiR-182-5p may exert oncogenic influence on NSCLC through regulating target genes such as HOXA9.

Keywords: miR-182-5p, Non-small cell lung cancer, RT-qPCR, miRNA-seq, miRNA-chips, HOXA9

\footnotetext{
* Correspondence: huxiaohua@gxmu.edu.cn; chengang@gxmu.edu.cn

'Li Gao, Shi-bai Yan, Xiao-hua Hu and Gang Chen contributed equally to this work.

${ }^{2}$ Department of Medical Oncology, the First Affiliated Hospital of Guangxi Medical University, Zhuang Autonomous Region, Nanning 530021, Guangxi China

'Department of Pathology, the First Affiliated Hospital of Guangxi Medical University, Zhuang Autonomous Region, Nanning 530021, Guangxi, China Full list of author information is available at the end of the article
}

(c) The Author(s). 2020 Open Access This article is distributed under the terms of the Creative Commons Attribution 4.0 International License (http://creativecommons.org/licenses/by/4.0/), which permits unrestricted use, distribution, and reproduction in any medium, provided you give appropriate credit to the original author(s) and the source, provide a link to the Creative Commons license, and indicate if changes were made. The Creative Commons Public Domain Dedication waiver (http://creativecommons.org/publicdomain/zero/1.0/) applies to the data made available in this article, unless otherwise stated. 


\section{Background}

According to data from the National Comprehensive Cancer Network, lung cancer (LC) is responsible for the majority of cancer-associated deaths worldwide [1]. There are two types of LC: non-small cell lung cancer (NSCLC) and small cell lung cancer [2]. Of these, NSLC is the most common and accounts for the majority cases of LC [1-8].

Although improvements in screening (i.e., diagnostic imaging and laboratory tests) and drug therapy have contributed greatly to NSCLC outcomes, the clinical outcome of NSCLC remains poor due to a lack of effective biomarkers for NSCLC [4]. At the time of diagnosis, most of patients have advanced stage disease because of atypical symptoms in the early stage of the disease [2]. Thus, NSCLC survival is poor, with 5-year survival lower than 20\% [5]. Therefore, the development of novel screening and therapeutic strategies are of crucial importance for NSCLC patients.

MicroRNAs (miRNAs) are small, noncoding RNAs that regulate gene expression by binding specifically to the complimentary sequence of target mRNAs in the 3' untranslated region ( $3^{\prime}$-UTR), thereby silencing the translation process and accelerating the degradation of target mRNAs [5, 8-16]. A number of previous studies demonstrated that miRNAs played essential roles in various cancers, including LC, via their effects on various biological events, such as differentiation, apoptosis, and proliferation, at the post-transcriptional level [9, 17-24]. Studies also reported that the miRNA miR-182-5p participated in the occurrence and progression of various human cancers [25-30]. In previous work, we demonstrated a tumor-promoting effect of upregulated miR182-5p in lung squamous cell carcinomas (LUSCs) [31].

The aim of the present study was to examine the clinicopathological value and molecular mechanisms of miR$182-5 p$ in non-small cell lung cancer (NSCLC). With this aim in mind, we examined miR-182-5p overexpression patterns in lung adenocarcinomas (LUADs) and NSCLC.

We expect that the current study will facilitate understanding of the role of miR-182-5p in the pathogenesis of NSCLC and its potential value as a marker of NSCLC subtypes.

\section{Methods}

Tissue collection from NSCLC patients

NSCLC tissue samples and paired noncancer tissue samples were obtained from 124 NSCLS patients

Table 1 MiR-182-5p expression in LUAD data from RT-qPCR

\begin{tabular}{|c|c|c|c|c|c|}
\hline \multicolumn{2}{|c|}{ Clinicopathological parameters } & \multirow{3}{*}{$\begin{array}{l}\mathrm{n} \\
101\end{array}$} & \multicolumn{3}{|c|}{ 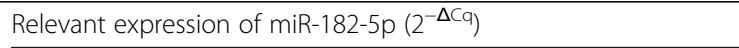 } \\
\hline & & & \multirow{2}{*}{$\begin{array}{l}\text { Mean } \pm \text { SD } \\
30.371 \pm 5.475\end{array}$} & \multirow{2}{*}{$\begin{array}{r}\text { t/F-value } \\
14.035\end{array}$} & \multirow{2}{*}{$\frac{p \text {-value }}{<0.001^{*}}$} \\
\hline Tissue & LUAD & & & & \\
\hline & Noncancerous & 101 & $22.908 \pm 3.728$ & & \\
\hline \multirow[t]{2}{*}{ Gender } & Male & 56 & $29.923 \pm 5.567$ & 1.150 & 0.253 \\
\hline & Female & 45 & $28.609 \pm 5.879$ & & \\
\hline \multirow[t]{2}{*}{ Age (years) } & $<60$ & 41 & $30.642 \pm 5.238$ & 1.964 & 0.053 \\
\hline & $\geq 60$ & 60 & $28.446 \pm 5.899$ & & \\
\hline \multirow[t]{2}{*}{ Smoke } & No & 26 & $31.159 \pm 5.435$ & 0.602 & 0.550 \\
\hline & Yes & 18 & $30.138 \pm 5.671$ & & \\
\hline \multirow[t]{2}{*}{ Tumor size } & $\leq 3 \mathrm{~cm}$ & 53 & $25.041 \pm 4.651$ & -13.541 & $<0.001^{*}$ \\
\hline & $>3 \mathrm{~cm}$ & 48 & $34.082 \pm 1.343$ & & \\
\hline \multirow[t]{2}{*}{ Vascular invasion } & No & 70 & $28.986 \pm 5.839$ & -0.927 & 0.356 \\
\hline & Yes & 31 & $30.130 \pm 5.441$ & & \\
\hline \multirow[t]{2}{*}{ TNM } & $|-| \mid$ & 44 & $26.730 \pm 5.442$ & -4.377 & $<0.001^{*}$ \\
\hline & III-IV & 57 & $31.350 \pm 5.114$ & & \\
\hline \multirow[t]{2}{*}{ Lymph node metastasis } & No & 45 & $26.478 \pm 5.243$ & -5.023 & $<0.001^{*}$ \\
\hline & Yes & 56 & $31.635 \pm 5.036$ & & \\
\hline \multirow[t]{3}{*}{ Pathological grading } & । & 17 & $27.642 \pm 5.863$ & $0.915^{b}$ & 0.404 \\
\hline & $\|$ & 61 & $29.753 \pm 5.713$ & & \\
\hline & III & 23 & $29.489 \pm 5.641$ & & \\
\hline
\end{tabular}


(LUADs, $n=101$; LUSCs, $n=23$ ) undergoing surgery at the First Affiliated Hospital of Guangxi Medical University between January 2012 and February 2014. All the NSCLC cases were diagnosed by two independent pathologists with no involvement in the study. There were 74 males and 50 females in this study.

The study was approved by the ethics committee of the First Affiliated Hospital of Guangxi Medical University, and written informed consent was obtained from all the patients.

All 124 NSCLC tissues were formalin fixed and paraffin embedded for subsequent experiments.

In-house real-time quantitative polymerase chain reaction (RT-qPCR)

Isolation and normalization of RNA, and the RTqPCR were carried out as previously described [3138]. RNU6B was selected as an endogenous control and reference gene of miR-182-5p [34]. The sequences of miR-182-5p and RNU6B were as follows:
miR-182-5p: UUUGGCAAUGGUAGAACUCACACU (Cat. no. 4427975-002334); RNU6B: CGCAAG GAUGACACGCAAAUUCGUGAAGCGUUCCAUAU UUUU (Cat. no. 4427975-000490). The relative miR182-5p expression level was computed using the method of $2^{-\Delta c q}$. The statistical analysis for the RTqPCR was as described previously [39].

\section{MiR-182-5p expression in NSCLC using miRNA-seq data}

Level 3 IlluminaHiSeq miRNA-seq data on miR-182$5 p$ expression in NSCLC were obtained from recomputed and normalized the cancer genome atlas (TCGA) data in UCSC Xena (https://xena.ucsc.edu/). Alterations in the expression of miR-182-5p in LUADs, non-LUADs, NSCLC, and non-NSCLC, in addition to the distribution of miR-182-5p in groups of different clinical variables, were calculated to determine the clinical significance of miR-182-5p. The statistical analysis of the miRNA-seq data has been described in detail elsewhere [39].

Table 2 MiR-182-5p expression in NSCLC data from RT-qPCR

\begin{tabular}{|c|c|c|c|c|c|}
\hline \multicolumn{2}{|c|}{ Clinicopathological parameters } & \multirow{3}{*}{$\begin{array}{l}\mathrm{n} \\
124\end{array}$} & \multicolumn{3}{|c|}{ Relevant expression of miR-182-5p (2 $\left.2^{-\Delta C a}\right)$} \\
\hline & & & \multirow{2}{*}{$\frac{\text { Mean } \pm \text { SD }}{29.615 \pm 5.616}$} & \multirow{2}{*}{$\frac{t / F-v a l u e}{13.979}$} & \multirow{2}{*}{$\frac{p \text {-value }}{<0.001^{*}}$} \\
\hline Tissue & NSCLC & & & & \\
\hline & Noncancerous & 124 & $22.859 \pm 3.669$ & & \\
\hline \multirow[t]{2}{*}{ Gender } & Male & 74 & $30.144 \pm 5.497$ & 1.278 & 0.204 \\
\hline & Female & 50 & $28.833 \pm 5.755$ & & \\
\hline \multirow[t]{2}{*}{ Age (years) } & $<60$ & 56 & $30.913 \pm 5.052$ & 2.413 & $0.017^{*}$ \\
\hline & $\geq 60$ & 68 & $28.547 \pm 5.864$ & & \\
\hline \multirow[t]{2}{*}{ Smoke } & No & 38 & $31.184 \pm 5.185$ & 0.720 & 0.474 \\
\hline & Yes & 29 & $30.237 \pm 5.530$ & & \\
\hline \multirow[t]{2}{*}{ Histological type } & Adenocarcinoma & 101 & $29.337 \pm 5.717$ & -1.245 & 0.221 \\
\hline & Squamous carcinoma & 23 & $30.836 \pm 5.086$ & & \\
\hline \multirow[t]{2}{*}{ Tumor size } & $\leq 3 \mathrm{~cm}$ & 60 & $24.995 \pm 4.570$ & -14.353 & $<0.001^{*}$ \\
\hline & $>3 \mathrm{~cm}$ & 64 & $33.947 \pm 1.620$ & & \\
\hline \multirow[t]{2}{*}{ Vascular invasion } & No & 90 & $29.456 \pm 5.720$ & -0.512 & 0.609 \\
\hline & Yes & 34 & $30.037 \pm 5.391$ & & \\
\hline \multirow[t]{2}{*}{ TNM } & $|-| \mid$ & 54 & $27.131 \pm 5.424$ & -4.632 & $<0.001^{*}$ \\
\hline & III-IV & 70 & $31.532 \pm 5.007$ & & \\
\hline \multirow[t]{2}{*}{ Lymph node metastasis } & No & 56 & $26.621 \pm 5.128$ & -6.095 & $<0.001^{*}$ \\
\hline & Yes & 68 & $32.081 \pm 4.759$ & & \\
\hline \multirow[t]{3}{*}{ Pathological grading } & । & 17 & $27.642 \pm 5.863$ & $1.246^{\mathrm{a}}$ & 0.291 \\
\hline & $\|$ & 77 & $29.853 \pm 5.721$ & & \\
\hline & III & 30 & $30.124 \pm 5.131$ & & \\
\hline
\end{tabular}

NSCLC: non-small cell lung cancer; SD: standard deviation a One-way analysis of variance (ANOVA) was performed

* The results were statistically significant $(P<0.05)$ 


\section{Analysis of miR-182-5p expression in NSCLC based on data in public miRNA-chip databases}

The gene expression omnibus (GEO) database was searched for data deposited up to 12 April 2019. The search terms used were as follows: (cancer OR carcinoma OR adenocarcinoma OR tumour OR tumor OR malignanc* OR neoplas*) AND (lung OR pulmonary OR respiratory OR respiration OR aspiration OR bronchi OR bronchioles OR alveoli OR pneumocytes OR "air way"). All miRNAchips meeting the listed inclusion criteria were considered eligible for inclusion in the study: (1) the experimental subjects were humans, and (2) miR-182-5p expression was reported for both NSCLC and healthy lung tissues. Only studies where the NSCLC sample size exceeded three and included paired healthy tissues were included. The data extraction and statistical analysis of miR-182-5p expression have been described in detail elsewhere [40].

\section{Search of the scientific literature for data on miR-182-5p expression in NSCLC}

We searched the literature for information of miR-1825 p differential expression in NSCLC and noncancer lung tissues. The following databases were searched using the keywords: (cancer OR carcinoma OR adenocarcinoma OR tumour OR tumor OR malignanc* OR neoplas*) AND (Lung OR pulmonary OR respiratory OR respiration OR aspiration OR bronchi OR bronchioles OR alveoli OR pneumocytes OR "air way") AND (miR-182 OR miRNA-182 OR microRNA-182 OR miR182 OR miRNA182 OR microRNA182 OR “miR 182" OR “miRNA 182" OR “microRNA 182"OR miR-182-5p OR miRNA-182-5p OR microRNA-182-5p): PubMed, Wiley Online Library, EBSCO, Cochrane Central Register of Controlled Trials, Web of Science, Google Scholar, Ovid, EMBASE, and LILACS. Studies that reported expression data for miR-182-5p in NSCLC subtypes and paired noncancer samples were included in a meta-analysis. The meta-analysis included all the in-house RT-qPCR, miRNA-seq, miRNA-chip, and literature data. Pooling of the standard mean difference (SMD) and creation of summary receiver operating characteristic (SROC) curves from all the included studies was done to determine the differential expression miR-182-5p and its potential utility in distinguishing NSCLC and noncancer

Table 3 MiR-182-5p expression in LUAD from miRNA-seq data

\begin{tabular}{|c|c|c|c|c|c|}
\hline \multirow[t]{2}{*}{ Characteristics } & & \multirow[t]{2}{*}{$n$} & \multicolumn{3}{|c|}{ Relevant expression of miR-182-5p ( $\left.\log _{2} x\right)$} \\
\hline & & & Mean \pm SD & t/F-value & P-value \\
\hline \multirow[t]{2}{*}{ Tissue } & LUAD & 448 & $14.273 \pm 0.947$ & 17.368 & $<0.001^{*}$ \\
\hline & Noncancerous & 45 & $11.644 \pm 1.160$ & & \\
\hline \multirow[t]{2}{*}{ Gender } & Male & 209 & $14.259 \pm 0.902$ & -0.306 & 0.760 \\
\hline & Female & 239 & $14.286 \pm 0.987$ & & \\
\hline \multirow[t]{2}{*}{ Age(years) } & $\leq 50$ & 33 & $14.295 \pm 1.205$ & 0.175 & 0.862 \\
\hline & $>50$ & 396 & $14.257 \pm 0.932$ & & \\
\hline \multirow[t]{2}{*}{$\mathrm{T}$} & $\mathrm{T} 1+\mathrm{T} 2$ & 388 & $14.294 \pm 0.954$ & 0.679 & 0.497 \\
\hline & $\mathrm{T} 3+\mathrm{T} 4$ & 57 & $14.203 \pm 0.871$ & & \\
\hline \multirow[t]{2}{*}{ Nodes } & No & 293 & $14.252 \pm 0.966$ & -1.025 & 0.306 \\
\hline & Yes & 146 & $14.349 \pm 0.892$ & & \\
\hline \multirow[t]{2}{*}{ Metastasis } & No & 285 & $14.326 \pm 0.898$ & -0.366 & 0.715 \\
\hline & Yes & 19 & $14.404 \pm 1.027$ & & \\
\hline \multirow[t]{2}{*}{ Pathologic stage } & $|-| \mid$ & 351 & $14.249 \pm 0.958$ & -0.810 & 0.419 \\
\hline & ||$|-| V$ & 92 & $14.340 \pm 0.918$ & & \\
\hline \multirow[t]{5}{*}{ Anatomic neoplasm subdivision } & L-Lower & 70 & $14.229 \pm 0.825$ & $0.512^{\mathrm{a}}$ & 0.727 \\
\hline & L-Upper & 108 & $14.206 \pm 0.998$ & & \\
\hline & R-Lower & 85 & $14.214 \pm 0.940$ & & \\
\hline & R-Middle & 18 & $14.281 \pm 0.789$ & & \\
\hline & R-Uppr & 155 & $14.351 \pm 0.986$ & & \\
\hline \multirow[t]{2}{*}{ Tumor location } & Peripheral & 113 & $14.309 \pm 0.940$ & -0.743 & 0.459 \\
\hline & Central & 54 & $14.429 \pm 1.051$ & & \\
\hline
\end{tabular}

LUAD: lung adenocarcinoma; SD: standard deviation a One-way analysis of variance (ANOVA) was performed

* The results were statistically significant $(P<0.05)$ 
cases. Details on the data processing and statistical analysis in the meta-analysis have been described in previous studies $[40,41]$.

\section{Prediction of target genes}

An online program, MiRWalk v.2.0, which incorporates 12 prediction platforms (miRanda, Microt4, miRWalk, miRDB, miRbridge, miRMap, Pictar2, miRNAMap, PITA, RNAhybrid, RNA22, and Targetscan), was used for predicting the targets of miR-182-5p. Predicted genes that appeared in at least eight of the 12 prediction platforms were regarded as candidate targets of miR-182-5p.

\section{Functional annotation of candidate target genes of miR-} 182-5p and construction of a protein-protein interaction (PPI) network

Gene ontology (GO) and Kyoto Encyclopedia of Genes and Genomes (KEGG) pathway analyses were conducted using the ClusterProfiler package in $\mathrm{R}$ software v.3.5.2 to explore the enrichment of candidate target genes in biological process, cellular component, and molecular function pathways. Items with a $p<$ 0.05 were considered statistically significant. The top 15 significant biological process, cellular component, and molecular function terms, as well as the top 10 significant KEGG pathway terms, were visualized as a bubble plot and chord plot using the GOplot package of R software v.3.5.2. A PPI network was subsequently built using the Search Tool for the Retrieval of Interacting Genes to illustrate the interactions between target genes.

\section{Validation of miR-182-5p targeting of HOXA9}

In a previous study, we detected the expression level of HOXA9 in the same cohort of NSCLC patients using the RT-qPCR [42]. The primers for HOXA9

Table 4 MiR-182-5p expression in NSCLC from miRNA-seq data

\begin{tabular}{|c|c|c|c|c|c|}
\hline \multirow[t]{2}{*}{ Clinicopathological feature } & & \multirow[t]{2}{*}{$\mathrm{n}$} & \multicolumn{3}{|c|}{ Relevant expression of miR-182-5p ( $\left.\log _{2} x\right)$} \\
\hline & & & Mean $\pm S D$ & t/F-value & P-value \\
\hline \multirow[t]{2}{*}{ Tissue } & Lung cancer & 784 & $14.332 \pm 1.042$ & 21.214 & $<0.001^{*}$ \\
\hline & Noncancerous & 89 & $11.962 \pm 0.994$ & & \\
\hline \multirow[t]{2}{*}{ Histological type } & Adenocarcinoma & 448 & $14.273 \pm 0.947$ & -1.785 & 0.075 \\
\hline & Squamous carcinoma & 336 & $14.411 \pm 1.154$ & & \\
\hline \multirow[t]{2}{*}{ Gender } & Male & 460 & $14.367 \pm 1.042$ & 1.137 & 0.256 \\
\hline & Female & 324 & $14.282 \pm 1.042$ & & \\
\hline \multirow[t]{2}{*}{ Age(years) } & $\leq 60$ & 213 & $14.396 \pm 1.040$ & 1.169 & 0.243 \\
\hline & $>60$ & 546 & $14.297 \pm 1.055$ & & \\
\hline \multirow[t]{2}{*}{ T } & $\mathrm{T} 1+\mathrm{T} 2$ & 654 & $14.358 \pm 1.038$ & 1.242 & 0.214 \\
\hline & $\mathrm{T} 3+\mathrm{T} 4$ & 127 & $14.232 \pm 1.051$ & & \\
\hline \multirow[t]{2}{*}{ Nodes } & No & 509 & $14.315 \pm 1.050$ & -1.182 & 0.238 \\
\hline & Yes & 260 & $14.408 \pm 1.006$ & & \\
\hline \multirow[t]{2}{*}{ Metastasis } & No & 540 & $14.376 \pm 1.041$ & 0.328 & 0.743 \\
\hline & Yes & 21 & $14.302 \pm 1.029$ & & \\
\hline \multirow[t]{2}{*}{ Pathologic stage } & $|-| \mid$ & 631 & $14.320 \pm 1.063$ & -0.481 & 0.631 \\
\hline & III-IV & 145 & $14.366 \pm 0.962$ & & \\
\hline \multirow[t]{5}{*}{ Anatomic organ subdivision } & L-Lower & 112 & $14.285 \pm 1.029$ & $0.662^{a}$ & 0.618 \\
\hline & L-Upper & 198 & $14.240 \pm 0.995$ & & \\
\hline & R-Lower & 160 & $14.390 \pm 1.073$ & & \\
\hline & R-Middle & 29 & $14.416 \pm 1.008$ & & \\
\hline & R-Uppr & 249 & $14.359 \pm 1.026$ & & \\
\hline \multirow[t]{2}{*}{ Tumor location } & Peripheral & 187 & $14.342 \pm 1.013$ & -0.210 & 0.834 \\
\hline & Central & 162 & $14.366 \pm 1.130$ & & \\
\hline
\end{tabular}

NSCLC: non-small cell lung cancer; SD: standard deviation

${ }^{a}$ One-way analysis of variance (ANOVA) was performed

* The results were statistically significant $(P<0.05)$ 
Table 5 Characteristics of included GEO miRNA-chips

\begin{tabular}{|c|c|c|c|c|c|c|c|c|c|c|c|c|c|c|}
\hline & $\begin{array}{l}\text { First } \\
\text { author }\end{array}$ & $\begin{array}{l}\text { Experiment } \\
\text { type }\end{array}$ & $\begin{array}{l}\text { Sample } \\
\text { type }\end{array}$ & Platform & $\begin{array}{l}\text { Cancer } \\
\text { (N) }\end{array}$ & $\begin{array}{l}\text { Cancer } \\
\text { (M) }\end{array}$ & $\begin{array}{l}\text { Cancer } \\
\text { (SD) }\end{array}$ & $\begin{array}{l}\text { Noncancer } \\
(\mathrm{N})\end{array}$ & $\begin{array}{l}\text { Noncancer } \\
\text { (M) }\end{array}$ & $\begin{array}{l}\text { Noncancer } \\
\text { (SD) }\end{array}$ & TP & FP & $\mathrm{FN}$ & $\overline{\mathrm{TN}}$ \\
\hline GSE14936 & Seike M & $\begin{array}{l}\text { Non-coding RNA } \\
\text { profiling by array }\end{array}$ & tissue & GPL8879 & 10 & 7.763 & 0.850 & 9 & 8.137 & 0.819 & 8 & 7 & 2 & 2 \\
\hline GSE15008 & $\operatorname{Tan} X$ & $\begin{array}{l}\text { Non-coding RNA } \\
\text { profiling by array }\end{array}$ & tissue & GPL2009 & 187 & 11.401 & 1.255 & 188 & 9.697 & 0.867 & 44 & 1 & 143 & 187 \\
\hline GSE16512 & Lodes MJ & $\begin{array}{l}\text { Non-coding RNA } \\
\text { profiling by array }\end{array}$ & serum & GPL8686 & 3 & -0.024 & 0.031 & 14 & -0.338 & 0.23 & 1 & 1 & 2 & 13 \\
\hline GSE17681 & Keller A & miRNA Profiling & serum & GPL9040 & 17 & 12.652 & 0.756 & 19 & 12.174 & 0.753 & 7 & 1 & 10 & 18 \\
\hline GSE18692A & $\begin{array}{l}\text { Puisségur } \\
\text { MP }\end{array}$ & $\begin{array}{l}\text { Non-coding RNA } \\
\text { profiling by array }\end{array}$ & tissue & GPL4717 & 7 & 0.458 & 0.304 & 7 & 0.251 & 0.153 & 5 & 1 & 2 & 6 \\
\hline GSE18692B & $\begin{array}{l}\text { Puisségur } \\
\text { MP }\end{array}$ & $\begin{array}{l}\text { Non-coding RNA } \\
\text { profiling by array }\end{array}$ & tissue & GPL4718 & 13 & 0.288 & 0.343 & 13 & 0.403 & 0.34 & 10 & 11 & 3 & 2 \\
\hline GSE19945 & Ohba T & $\begin{array}{l}\text { Non-coding RNA } \\
\text { profiling by array }\end{array}$ & tissue & GPL9948 & 20 & -0.325 & 1.781 & 8 & -2.799 & 0.554 & 15 & 0 & 5 & 8 \\
\hline GSE24709 & $\begin{array}{l}\text { Andreas } \\
\text { Keller }\end{array}$ & $\begin{array}{l}\text { Non-coding RNA } \\
\text { profiling by array }\end{array}$ & serum & GPL9040 & 28 & 12.253 & 0.532 & 19 & 11.626 & 0.775 & 17 & 0 & 11 & 19 \\
\hline GSE27486 & $\begin{array}{l}\text { Santosh } \\
\text { Kumar } \\
\text { Patnaik }\end{array}$ & $\begin{array}{l}\text { Non-coding RNA } \\
\text { profiling by array }\end{array}$ & serum & GPL11432 & 22 & 5.680 & 0.428 & 23 & 5.731 & 0.646 & 11 & 10 & 12 & 13 \\
\hline GSE27705 & $\begin{array}{l}\text { Chris } \\
\text { Fenton }\end{array}$ & $\begin{array}{l}\text { Non-coding RNA } \\
\text { profiling by array }\end{array}$ & tissue & GPL11432 & 20 & 0.106 & 0.934 & 10 & -1.187 & 0.196 & 19 & 1 & 1 & 9 \\
\hline GSE29248 & lina ma & $\begin{array}{l}\text { Non-coding RNA } \\
\text { profiling by array }\end{array}$ & tissue & GPL8179 & 6 & 12.643 & 0.704 & 6 & 11.099 & 2.171 & 3 & 0 & 3 & 6 \\
\hline GSE31568 & $\begin{array}{l}\text { Andreas } \\
\text { Keller }\end{array}$ & $\begin{array}{l}\text { Non-coding RNA } \\
\text { profiling by array }\end{array}$ & serum & GPL9040 & 32 & 12.173 & 0.607 & 70 & 11.847 & 0.972 & 12 & 5 & 20 & 65 \\
\hline GSE33045 & $\begin{array}{l}\text { Sonia } \\
\text { Molina- } \\
\text { Pinelo }\end{array}$ & $\begin{array}{l}\text { Expression } \\
\text { profiling by RT- } \\
\text { PCR }\end{array}$ & serum & GPL13987 & 12 & 12.618 & 1.642 & 8 & 13.291 & 1.223 & 12 & 7 & 0 & 1 \\
\hline GSE36681 & $\begin{array}{l}\text { Jin Sung } \\
\text { Jang }\end{array}$ & $\begin{array}{l}\text { Non-coding RNA } \\
\text { profiling by array }\end{array}$ & tissue & GPL8179 & 103 & 12.151 & 1.215 & 103 & 11.282 & 1.232 & 16 & 1 & 87 & 102 \\
\hline GSE40738 & $\begin{array}{l}\text { Santosh } \\
\text { Kumar } \\
\text { Patnaik }\end{array}$ & $\begin{array}{l}\text { Non-coding RNA } \\
\text { profiling by array }\end{array}$ & serum & GPL16016 & 81 & 5.225 & 0.581 & 56 & 5.025 & 0.675 & 8 & 1 & 73 & 55 \\
\hline GSE46729 & Zongli Xu & $\begin{array}{l}\text { Non-coding RNA } \\
\text { profiling by array }\end{array}$ & serum & GPL8786 & 24 & 4.530 & 0.227 & 24 & 4.423 & 0.215 & 5 & 1 & 19 & 23 \\
\hline GSE47525 & $\begin{array}{l}\text { Maikel } \\
\text { Wouters }\end{array}$ & $\begin{array}{l}\text { Non-coding RNA } \\
\text { profiling by array }\end{array}$ & tissue & GPL17222 & 18 & 4.927 & 0.716 & 14 & 4.727 & 0.412 & 7 & 1 & 11 & 13 \\
\hline GSE48414 & $\begin{array}{l}\text { Maria } \\
\text { Moksnes } \\
\text { Bjaanæs }\end{array}$ & $\begin{array}{l}\text { Non-coding RNA } \\
\text { profiling by array }\end{array}$ & tissue & GPL16770 & 154 & -0.364 & 2.547 & 20 & -3.548 & 2.166 & 120 & 0 & 34 & 20 \\
\hline GSE51853 & $\begin{array}{l}\text { Takashi } \\
\text { Takahashi }\end{array}$ & $\begin{array}{l}\text { Non-coding RNA } \\
\text { profiling by array }\end{array}$ & tissue & GPL7341 & 124 & 1.177 & 1.045 & 5 & -1.459 & 0.381 & 120 & 0 & 4 & 5 \\
\hline GSE53882 & $\begin{array}{l}\text { Heng-Ying } \\
\text { Pu }\end{array}$ & $\begin{array}{l}\text { Expression } \\
\text { profiling by array }\end{array}$ & tissue & GPL18130 & 397 & 1.245 & 0.446 & 151 & 1.172 & 0.428 & 11 & 1 & 386 & 150 \\
\hline GSE56036 & $\begin{array}{l}\text { Satoshi } \\
\text { Kondo }\end{array}$ & $\begin{array}{l}\text { Non-coding RNA } \\
\text { profiling by array }\end{array}$ & tissue & GPL15446 & 28 & 6.397 & 1.319 & 27 & 4.166 & 0.663 & 25 & 1 & 3 & 26 \\
\hline GSE61741 & $\begin{array}{l}\text { Andreas } \\
\text { Keller }\end{array}$ & $\begin{array}{l}\text { Non-coding RNA } \\
\text { profiling by array }\end{array}$ & serum & GPL9040 & 72 & 12.342 & 0.656 & 94 & 12.302 & 0.514 & 26 & 25 & 46 & 69 \\
\hline GSE68951 & $\begin{array}{l}\text { Christina } \\
\text { Backes }\end{array}$ & $\begin{array}{l}\text { Non-coding RNA } \\
\text { profiling by array }\end{array}$ & serum & GPL16770 & 203 & 1.225 & 0.336 & 12 & 1.149 & 0.144 & 92 & 1 & 111 & 11 \\
\hline GSE74190 & Lu Shaohua & $\begin{array}{l}\text { Non-coding RNA } \\
\text { profiling by array }\end{array}$ & tissue & GPL19622 & 66 & 0.761 & 1.650 & 44 & -3.404 & 2.568 & 36 & 1 & 30 & 43 \\
\hline GSE93300 & qu lili & $\begin{array}{l}\text { Non-coding RNA } \\
\text { profiling by array }\end{array}$ & tissue & GPL21576 & 9 & -6.044 & 0.938 & 4 & -8.187 & 0.885 & 8 & 0 & 1 & 4 \\
\hline
\end{tabular}


and the internal control: glyceraldehyde-3-phosphate dehydrogenase (GAPDH) were as follows: $5^{\prime}$ GCTGAGAATGAGAGCGGC-3' (HOXA9 forward); 5'-CAGTTCCAGGGTCTGGTGTT-3' (HOXA9 reverse); 5-'TGCACCACCAACTGCTTA-3' (GAPDH forward); and 5'-GGATGCAGGGATGATGTTC-3' (GAPDH reverse). The student's paired $t$ test in SPSS v.22.0 was performed to compare the expression levels of HOXA9 and miR-182-5p. The correlation between HOXA9 and miR-182-5p expression was assessed using Pearson's correlation test in GraphpadPrism v.7.0.

Data on predictive binding sites between HOXA9 and miR-182-5p were obtained from TargetScanHuman v.7.2. A dual luciferase reporter assay was performed to validate the direct target binding between HOXA9 and miR-182-5p. The 3'UTR of HOXA9 (wild type or mutation type) comprising putative miR-182-5p binding sites was cloned into a psiCHECK-2 luciferase reporter vector (Promega, USA) to generate psiCHECK-HOXA9 3'UTRs or psiCHECK-HOXA9-mut 3'UTRs. HEK-293 T cells were co-transfected with an miR-182-5p mimic, a negative mimic control, and a reporter vector of the psiCHECK-HOXA9 3'UTR or psiCHECK-HOXA9-mut 3'UTR. After incubation for $27 \mathrm{~h}$, the luciferase activity was measured using dual luciferase assay (Promega, USA) according to the manufacturer's protocol. Luciferase activity was inferred based on the ratios of Renilla and firefly luciferase activity. Each experiment was repeated three times.

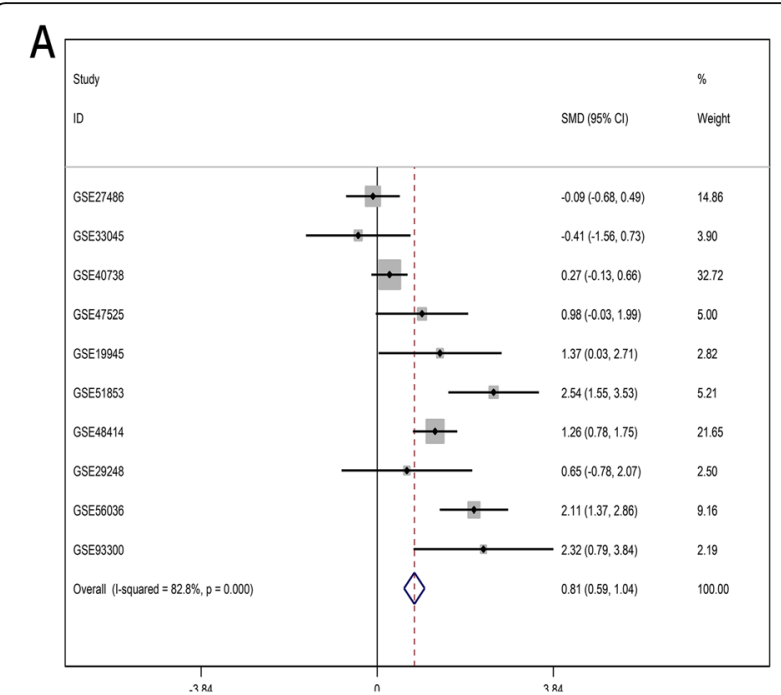

B
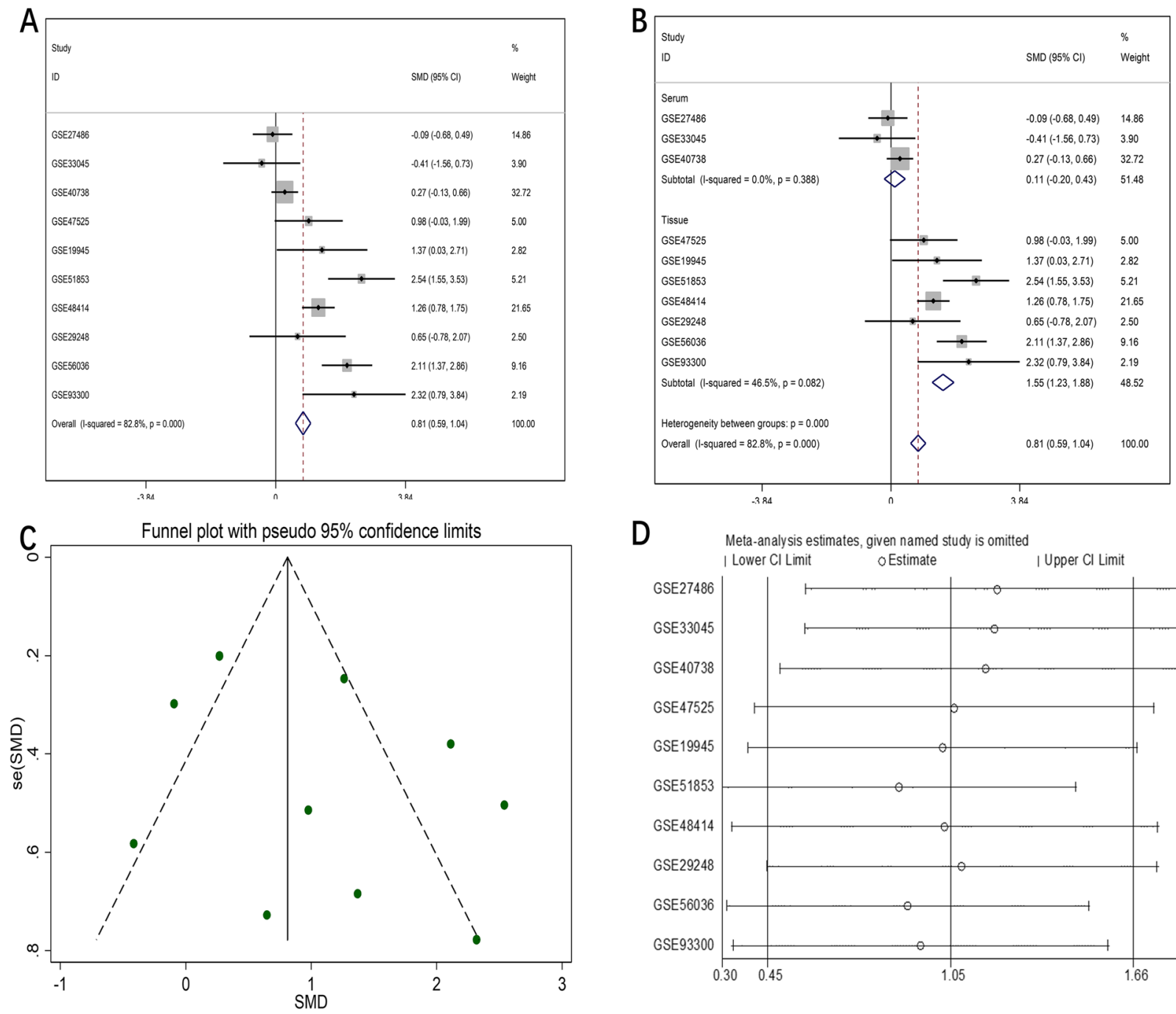

Meta-analysis estimates, given named study is omitted

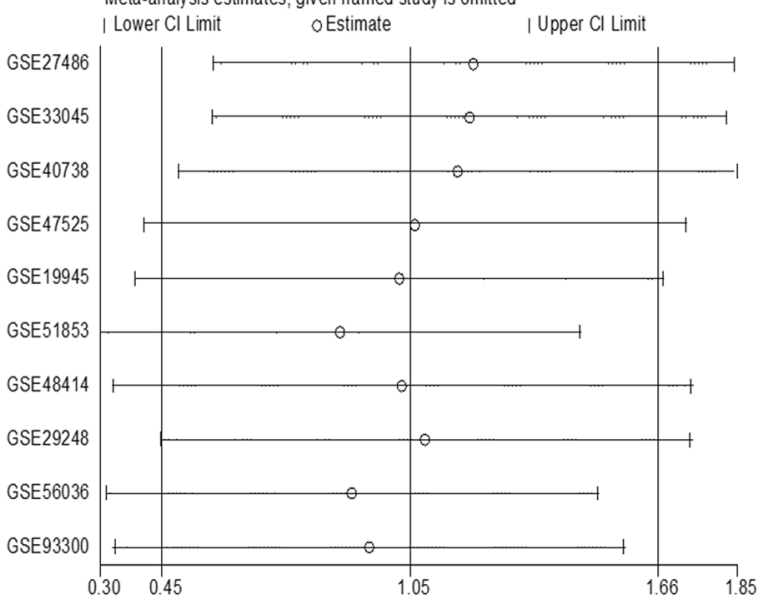

Fig. 1 Meta-analysis of miRNA-chip data for LUAD. a. Forest plot for overall SMD; b. Subgroup analysis; $\mathbf{c}$. Funnel plot of publication bias; $\mathbf{d}$. Sensitivity analysis 


\section{Results}

Evaluation of the clinicopathological significance of miR182-5p in NSCLC

\section{Analysis of $R T-q P C R$ data}

The analysis of the RT-qPCR data demonstrated that miR-182-5p was significantly upregulated in LUAD tissues as compared with that in paired non-LUAD lung tissues $(P<0.001$, Table 1 , Additional file 1 : Fig. S1). In general, miR-182-5p expression level was markedly higher in the majority of NSCLC tissues than in paired noncancer tissues $(P<0.001$, Table 2 , Additional file 2: Fig. S2). Overexpression of miR182-5p in LUAD and NSCLC was strongly associated with clinical parameters including tumor size, TNM stage, and lymph node metastasis $(P<0.05$, Tables 1 and 2). As shown by the ROC curve in Additional files 3 and 4: Fig. S3 and S4, miR-182-5p performed moderately well in differentiating LUAD from noncancer lung tissues and better in differentiating NSCLC tissues from noncancer lung tissues

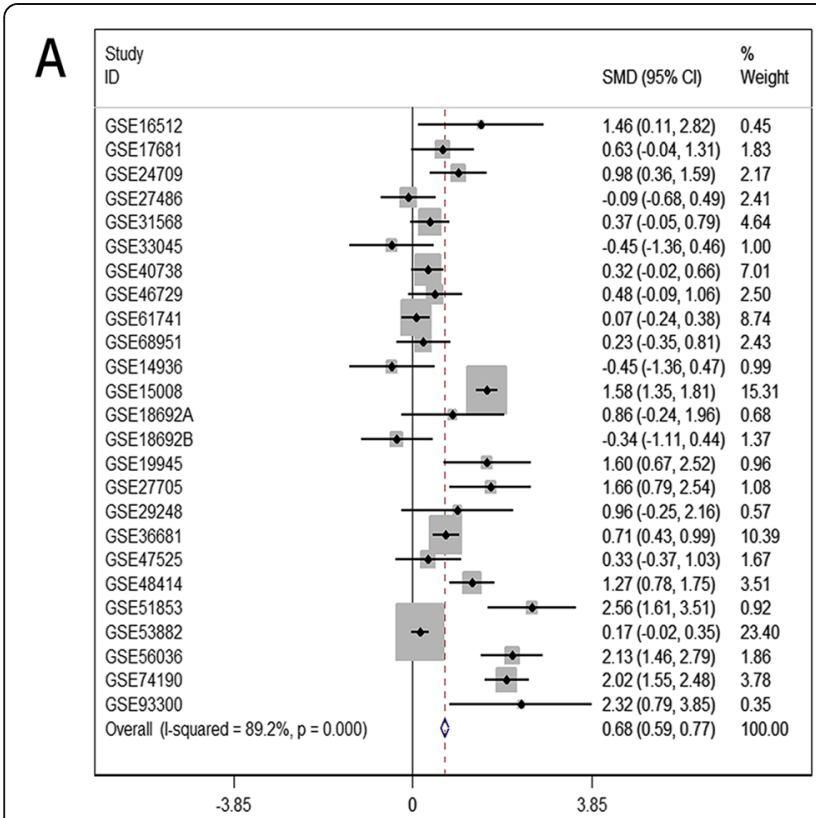

B
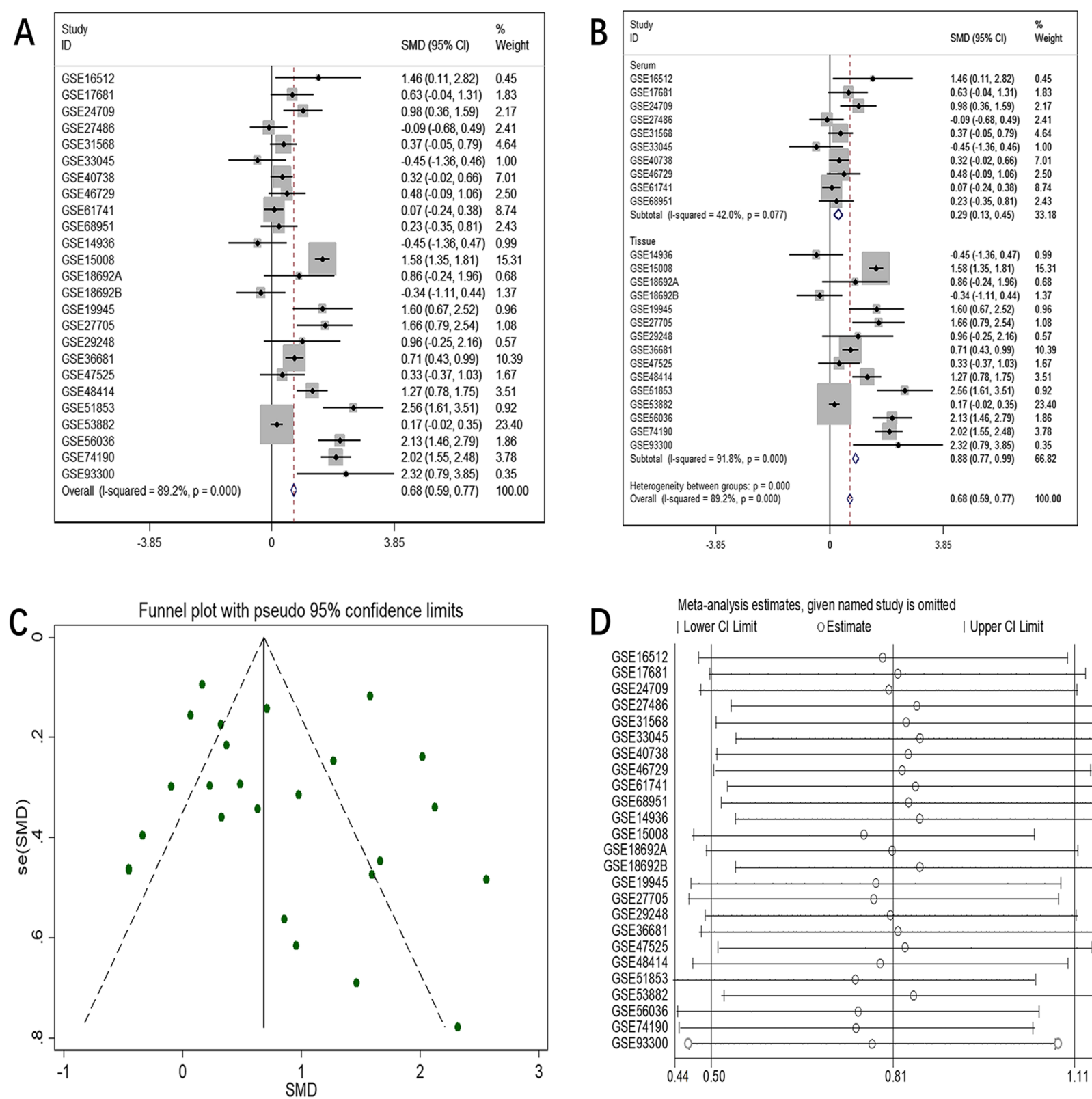

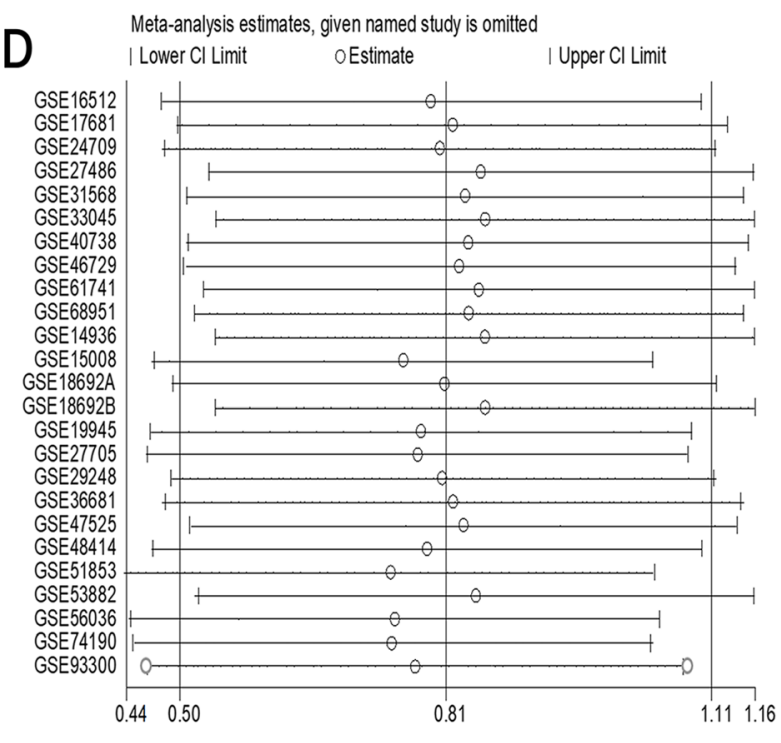

Fig. 2 Meta-analysis of miRNA-chip data for NSCLC. a. Forest plot for overall SMD; b. Subgroup analysis; c. Funnel plot of publication bias; d. Sensitivity analysis 
(area under the curve $[\mathrm{AUC}]=0.68$ and 0.82 , respectively). Kaplan-Meier survival curves revealed insignificant difference in the survival outcomes of LUAD and NSCLC patients with low or high miR182-5p expression (data not shown).

\section{Analysis of miRNA-seq data}

In total, miRNA-seq data were obtained for 784 NSCLC tissues (LUAD, $n=448$; LUSC, $n=336$ ) and 89 noncancer tissues. The clinicopathological significance of miR182-5p in LUAD and NSCLC is summarized in Table 3 and Table 4, respectively. In both LUAD and NSCLC tissues, miR-182-5p expression was markedly higher as compared with that in noncancer tissues $(P<0.001$,
Additional files 1 and 2: Fig. S1 and S2, Tables 3 and 4). As shown by the ROC curves in Additional files 3 and 4: Fig. S3 and S4, miR-182-5p expression appeared to distinguish LUAD and NSCLC from noncancer tissues (AUC $=0.98$ and $\mathrm{AUC}=0.96$, respectively). The KaplanMeier curves revealed no significant relationship between miR-182-5p expression and survival of NSCLC patients and LUAD patients (data not shown). Thus, the prognostic role of miR-182-5p in NSCLC remains unclear and needs to be studied in future work.

\section{Analysis of miRNA-chip data}

The initial search of the GEO database revealed 3204 studies. Of these, 248 studies were excluded

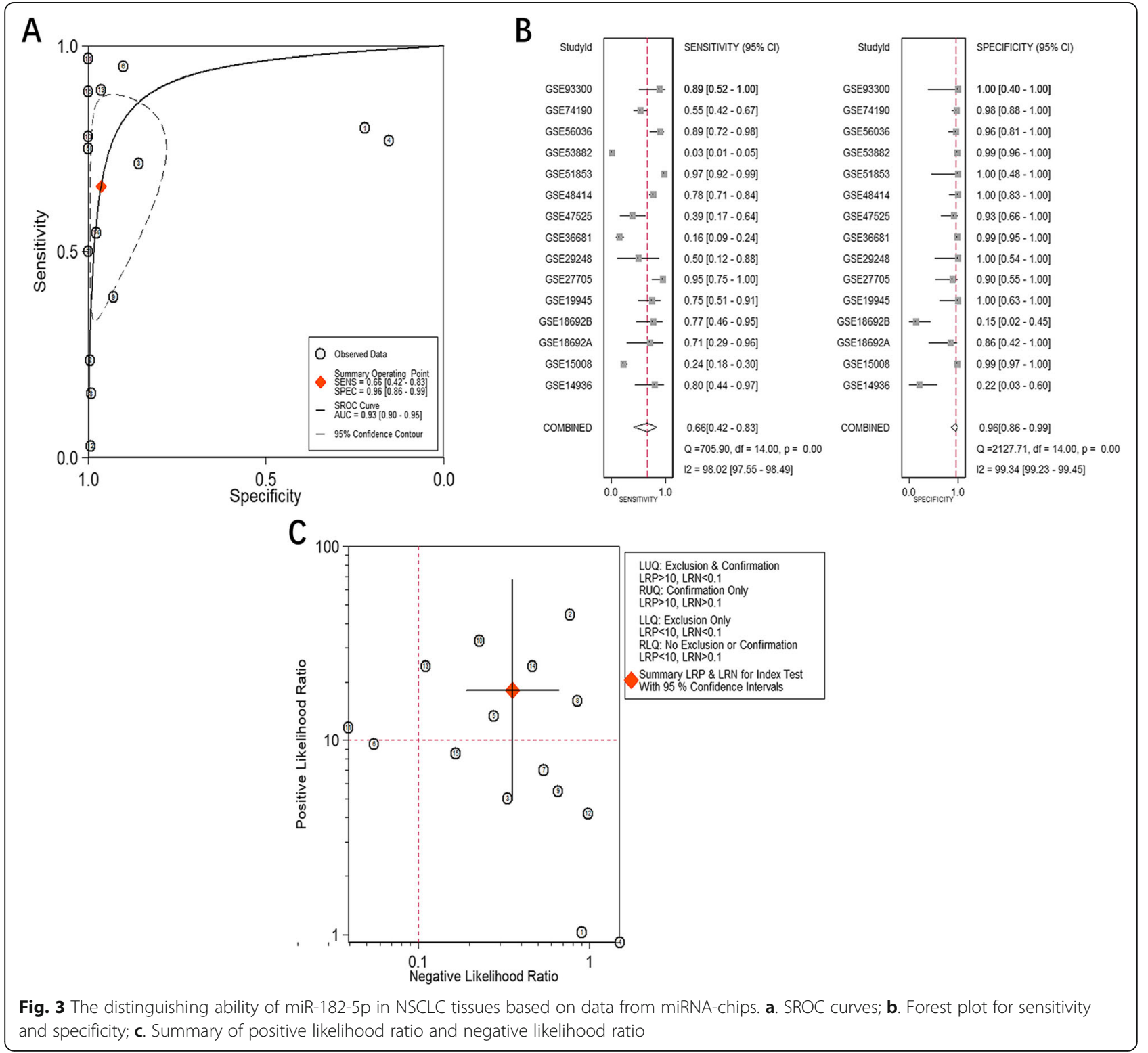


after screening the titles and abstracts. The final analysis included data of 25 eligible miRNA-chips on 1656 NSCLC samples (LUAD, $n=350$ ) and 948 noncancer samples. Several of the datasets that contained information on miR-182-5p expression in LUSC (GSE29248, GSE47525, GSE19945, GSE51853, and GSE74190) have been mined in previous work [31]. The characteristics of all the included miRNAchip data are listed in Table 5. The differential expression of miR-182-5p and the discriminatory ability of miR-182-5p in distinguishing LUAD and NSCLC tissues from noncancer tissues are displayed in Additional file 1-6: Fig. S1-6. The forest plots in Figs. 1 and 2 support a noticeable increase in the miR-182-5p level in LUAD and NSCLC as compared with the level in noncancer lung samples $(\mathrm{SMD}=$ $0.81,95 \%$ confidence interval $[\mathrm{CI}]=0.59-1.04$; $\mathrm{SMD}=0.68,95 \% \mathrm{CI}=0.59-0.77$ ).

Due to obvious heterogeneity among individual studies $\left(\mathrm{I}^{2}=82.8 \%, P<0.001 ; \mathrm{I}^{2}=89.2 \%, P<0.001\right)$, random-effect models were applied to merge the estimates. A subgroup analysis based on the source of the samples was employed to determine the origin of the heterogeneity. The pooled SMD of miR-182$5 \mathrm{p}$ expression in LUAD serum and tissue samples was $0.11(-0.20-0.43)$ and $1.55(1.23-1.88)$, respectively (Fig. 1). For NSCLC, the pooled SMD of miR182-5p expression in NSCLC serum and tissue samples was $0.29(0.13-0.45)$ and $0.88(0.77-0.99)$, respectively, suggesting that upregulation of miR-

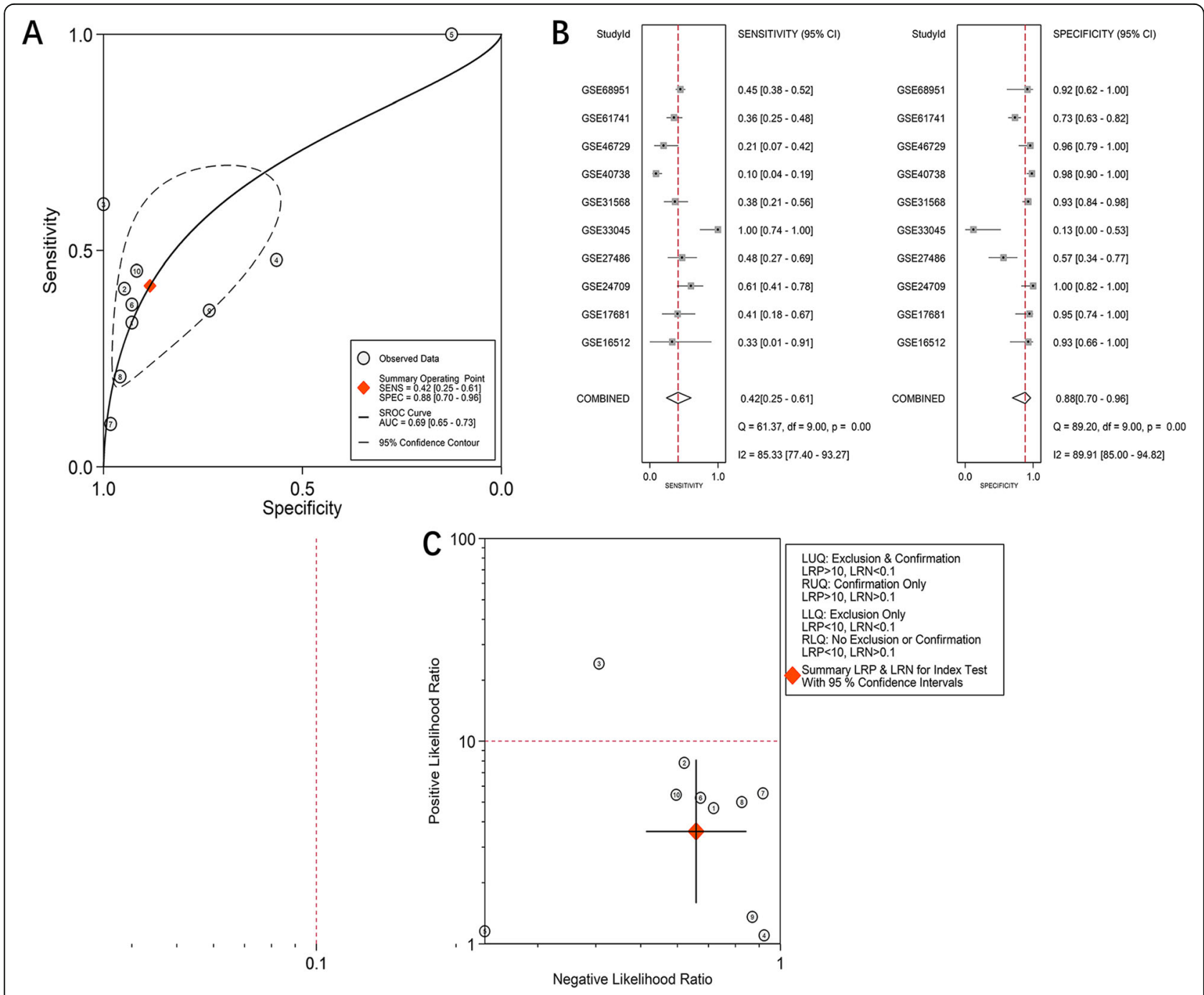

Fig. 4 The distinguishing value of miR-182-5p in NSCLC serum based on data from miRNA-chips. a. SROC curves; b. Forest plot for sensitivity and specificity; c. Summary of positive likelihood ratio and negative likelihood ratio 
182-5p expression was more obvious in the tissue samples than in the serum samples (Fig. 2). A subsequent sensitivity analysis and test for publication bias reported no eccentric study and no publication bias (Figs. 1 and 2). SROC curves accompanied by forest plots of the sensitivity, specificity, positive likelihood ratio, and negative likelihood ratio for NSCLC suggested that miR-182-5p expression in tissue better discriminated cancerous versus noncancerous tissue than miR-182-5p expression in serum $(\mathrm{AUC}=0.93$ and $\mathrm{AUC}=0.69$, respectively; Figs. 3 and 4 ).

Results of the meta-analysis incorporating in-house RTqPCR data, miRNA-seq data and miRNA-chip data

Based on the inclusion and exclusion criteria for the literature search, no studies were eligible for inclusion in the meta-analysis. Thus, the meta-analysis included 2564 NSCLC samples (LUAD, $n=899$ ) and 1161 noncancer samples obtained from the in-house RTqPCR, miRNA-seq, and miRNA-chip data analyses. The results of this comprehensive meta-analysis were consistent with those of the GEO meta-analysis, which confirmed upregulation of miR-182-5p in NSCLC tissues (SMD $=0.89(0.55-1.22)$ Figs. 6). Upregulation of miR-182-5p expression was more apparent in the tissue samples than in the serum samples, and miR-182-5p expression in the tissue samples had stronger discriminating power in terms of cancer versus noncancer than miR-182-5p expression did in serum samples (Figs. 3, 4, 5, 6 and 7).

\section{Molecular mechanism of miR-182-5p in NSCLC Functional annotation of candidate target genes in a PPI network}

In total, 774 genes were identified as candidate target genes in eight of the 12 prediction platforms (Additional file 7). As shown in Fig. 8 and Table 6, these candidate target genes were significantly enriched in biological processes, such as axonogenesis, axonal development, and Ras protein signal transduction. According to the chord plot in Fig. 8, these target genes appeared to mainly participate in pathways involved in axonal guidance, melanogenesis, and longevity regulation in multiple species. The complicated interactions between the candidate target genes were illustrated in a PPI network (Fig. 9).

\section{Validation of miR-182-5p targeting of HOXA9}

Among the candidate target genes, we selected HOXA9 and studied the relationship between it and miR-182-5p. As expected, HOXA9 was

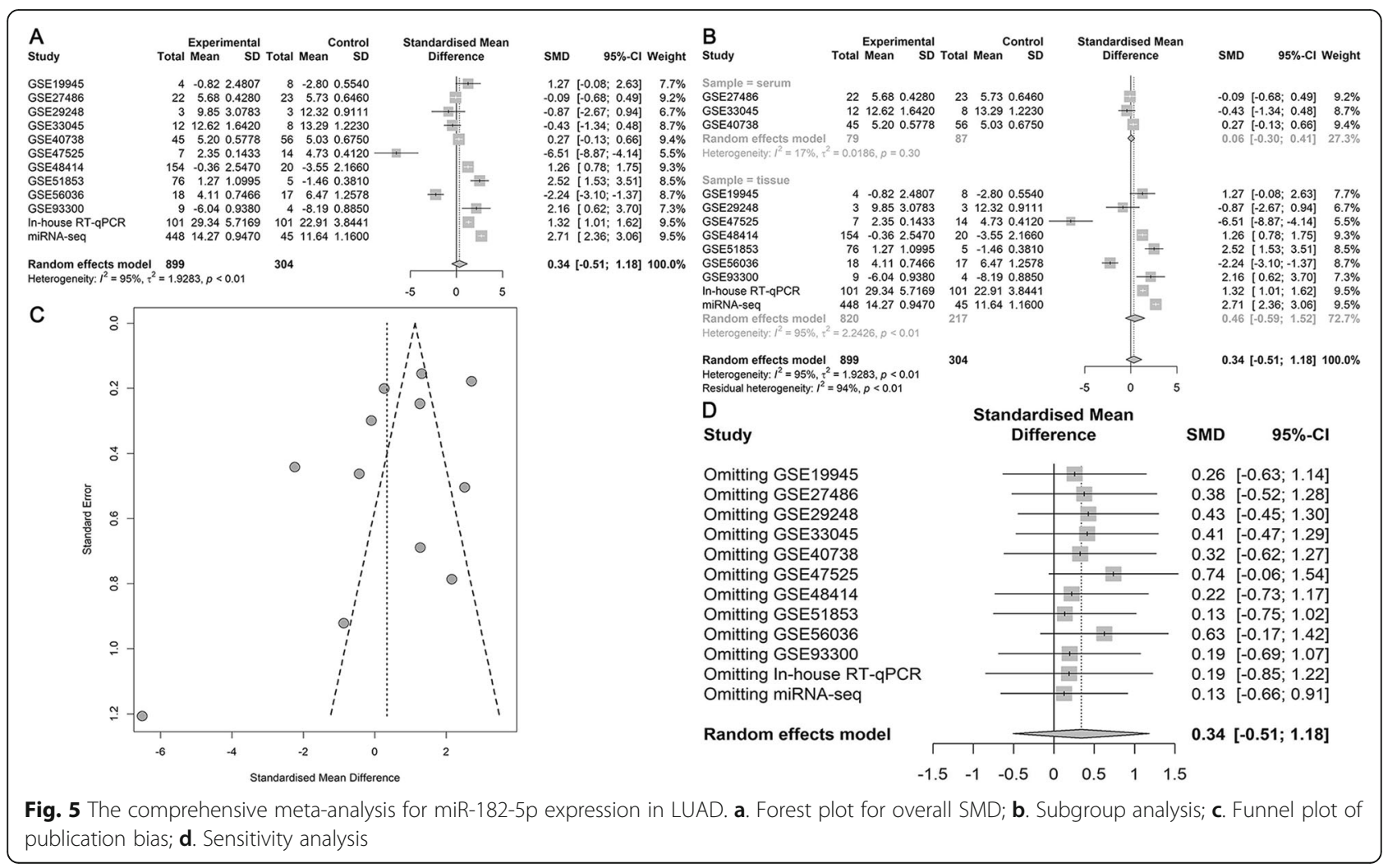




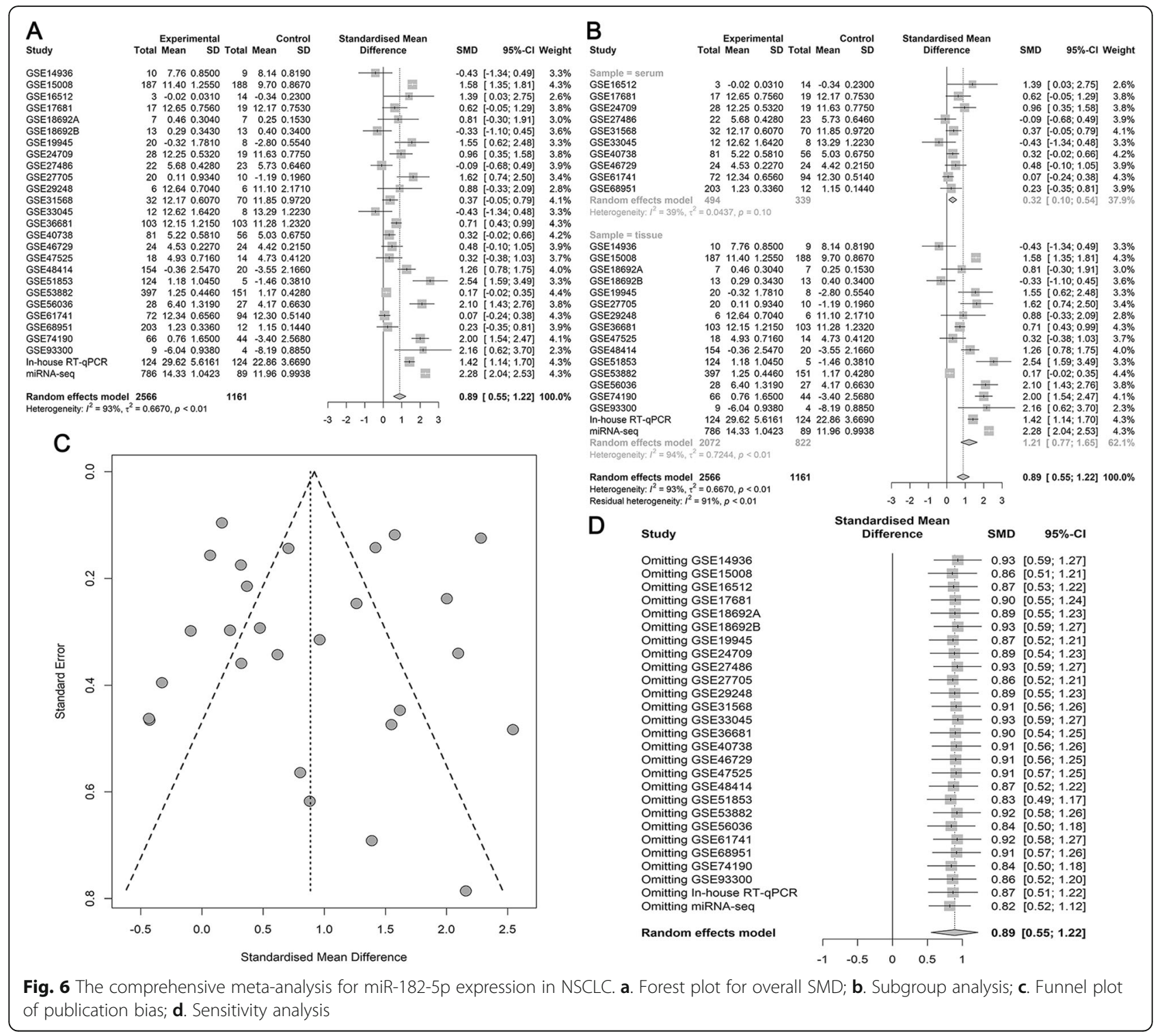

downregulated in 101 LUAD tissue samples and all 125 NSCLC tissue samples, as shown by the RTqPCR data $(P<0.001$, Figs. $10 \mathrm{~A}$ and $C)$. Importantly, miR-182-5p expression was negatively correlated with HOXA9 expression in 101 LUAD cases and 125 NSCLC cases $(r=-0.235, r=-0.247, P<0.001$, Figs. $10 \mathrm{~B}$ and $\mathrm{D}$ ). The predictive binding sites for miR-182-5p in the $3^{\prime}$-UTR of HOXA9 mRNA were imported from TargetScanHuman v.7.2. (Fig. 10E). According to a luciferase reporter assay, HEK-293 T cells co-transfected with psiCHECK-2/HOXA9 3'UTR and miR-182-5p mimics showed significantly reduced luciferase activity as compared with that in a control group $(P<0.01$, Fig. 10E).

\section{Discussion}

MiRNAs are important in the occurrence and development of LC [43-48]. Recent studies reported that dysregulation of the expression of multiple miRNAs, including miR-182-5p, was significantly correlated with tumorigenesis of LC [34]. Although several studies have demonstrated the oncogenic effect of miR-182-5p in NSCLC [49-52], interactions between miR-182-5p and target genes in NSCLC remained unclear. In particular, the molecular mechanism of miR-182-5p in NSCLC was unclear.

We previously demonstrated the oncogenic consequences of miR-182-5p in LUSCs through a combinatory analysis of data from RT-qPCR assays of 23 

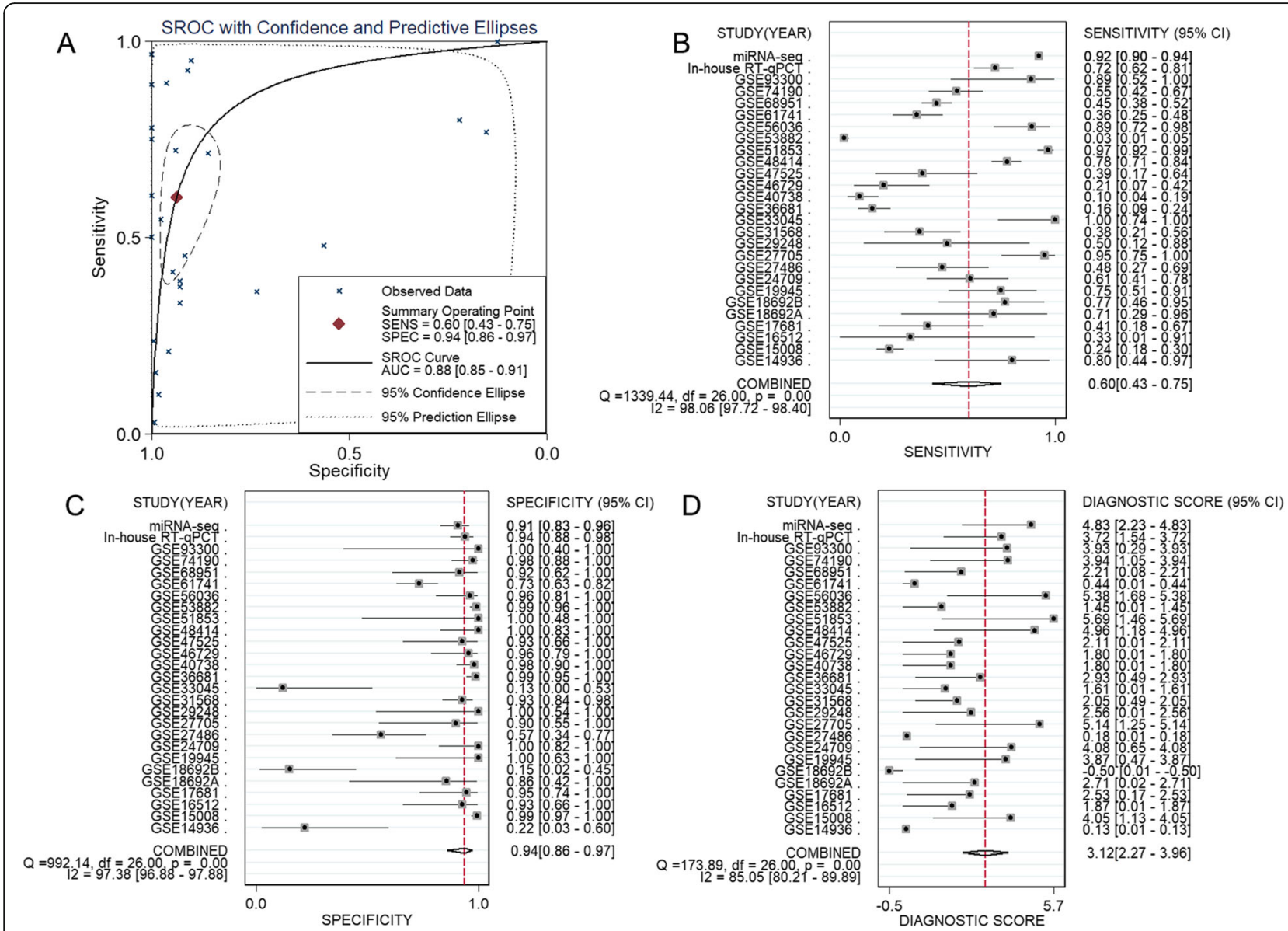

Fig. 7 The distinguishing power of miR-182-5p in NSCLC tissues based on data from all studies. a. SROC curves; b. Forest plot for sensitivity; c. Forest plot for specificity; d. Summary of diagnostic scores

samples obtained from LUSC patients treated in our hospital, miRNA-seq data, and miRNA-chip data. We hypothesized that the expression pattern of miR182-5p was similar in all the subtypes of NSCLC. In the present study, miR-182-5p was overexpressed in LUADs according to data from RT-qPCR assays of 124 samples obtained from NSCLC patients treated in our hospital, miRNA-seq data, and miRNA-chip data. Thus, we investigated the clinicopathological significance of miR-182-5p in NSCLC using in-house RT-qPCR data, miRNA-seq data, miRNA-chip data, and data in the scientific literature to explore the underlying molecular mechanism via a functional analysis of target genes.

The aforementioned data supported marked upregulation of miR-182-5p in NSCLC. Furthermore, the results of the RT-qPCR assays supported the influence of upregulated miR-182-5p on malignant clinical progression of NSCLC, which was consistent with the findings of previous studies [49-52]. It should be noted that there were some contradictions between the results of the RT-qPCR assays and those of the miRNA-seq data analysis. The discord might stem from different sources of patient cohorts and methods for calculating miR182-5p expression. The expression of miR-182-5p in the NSCLC samples analyzed using the in-house RT-qPCR was calculated based on the $2-\Delta$ cq algorithm In contrast, miR-182-5p expression in the miRNA-seq data was $\log 2$ (total_ reads per million +1 ) transformed in IlluminaHiSeq_miRNASeq platform. Nevertheless, miR-182-5p was upregulated in both the LUAD and NSCLC cohorts according to the miRNA-seq data, and miR-182-5p exhibited a trend toward elevated expression in samples from patients with malignant clinical progression of NSCLC, which was in agreement with the overall results. 


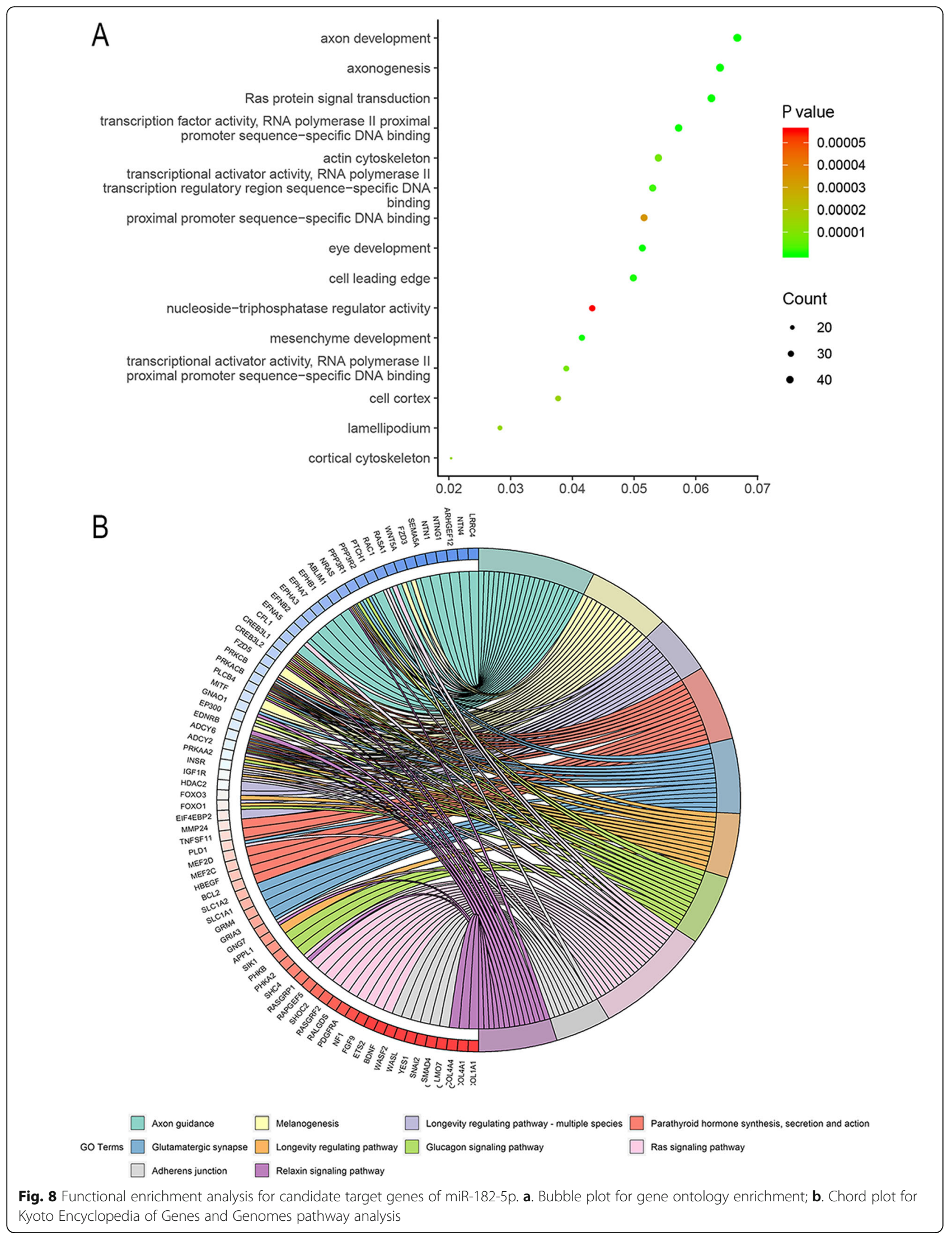


Table 6 Gene Ontology (GO) and Kyoto Encyclopedia of Genes and Genomes (KEGG) pathway analysis of candidate target genes of miR-182-5p

\begin{tabular}{|c|c|c|c|}
\hline Category & Item & Count & P-value \\
\hline GO-BP & axonogenesis & 46 & $<0.001$ \\
\hline GO-BP & axon development & 48 & $<0.001$ \\
\hline GO-BP & Ras protein signal transduction & 45 & $<0.001$ \\
\hline GO-BP & eye development & 37 & $<0.001$ \\
\hline GO-BP & mesenchyme development & 30 & $<0.001$ \\
\hline GO-CC & cell leading edge & 37 & $<0.001$ \\
\hline GO-CC & actin cytoskeleton & 40 & 0.002 \\
\hline GO-CC & cortical cytoskeleton & 15 & 0.002 \\
\hline GO-CC & lamellipodium & 21 & 0.002 \\
\hline GO-CC & cell cortex & 28 & 0.002 \\
\hline GO-MF & transcription factor activity, RNA polymerase II proximal promoter sequence-specific DNA binding & 41 & $<0.001$ \\
\hline GO-MF & transcriptional activator activity, RNA polymerase II transcription regulatory region sequence-specific DNA binding & 38 & $<0.001$ \\
\hline GO-MF & transcriptional activator activity, RNA polymerase II proximal promoter sequence-specific DNA binding & 28 & $<0.001$ \\
\hline GO-MF & proximal promoter sequence-specific DNA binding & 37 & $<0.001$ \\
\hline GO-MF & nucleoside-triphosphatase regulator activity & 31 & $<0.001$ \\
\hline KEGG & Axon guidance & 21 & $<0.001$ \\
\hline KEGG & Melanogenesis & 15 & $<0.001$ \\
\hline KEGG & Longevity regulating pathway - multiple species & 11 & $<0.001$ \\
\hline KEGG & Parathyroid hormone synthesis, secretion and action & 14 & $<0.001$ \\
\hline KEGG & Glutamatergic synapse & 14 & $<0.001$ \\
\hline
\end{tabular}

Note: BP: biological process; CC: cellular component; MF: molecular function

The SROC curves generated from all the datasets suggested that miR-182-5p could differentiate between LUAD or NSCLC and noncancer lung tissues. We believe that the large number of LC samples (NSCLC, $N=2564$; non cancer, $N=1161$ ) included in the present study support the findings.

To yield a deeper understanding of the molecular basis of the role of miR-182-5p in the carcinogenesis of NSCLC, we carried out functional annotations for candidate target genes and created a PPI network. The results indicated that miR-182-5p may exert an oncogenic influence on NSCLC via involvement in various biological processes, such as axonogenesis, axonal development, and Ras protein signal transduction, as well as in pathways including axonal guidance, melanogenesis, and longevity regulation in multiple species. The intricate regulatory network between the candidate target genes in the PPI network indicated that cooperation or antagonism between target genes may constitute an important link in the course of NSCLC.

Among the candidate target genes, HOXA9, a member of the HOX gene family, encodes a series of transcription factors with critical roles in cancer [53]. Previous research showed that HOXA9 had oncogenic functions in hematologic cancers and anticancer effects in breast cancer and NSCLC [54, 55]. In this study, to shed light on the regulatory relationship between miR-182-5p and HOXA9, we studied the expression level of HOXA9 in NSCLC and verified the relationships between miR-182-5p and HOXA9 through a correlation analysis and dual-luciferase reporter assay. The results showed that upregulation of miR-182-5p in LUAD or NSCLC was significantly correlated with downregulation of HOXA9 in LUAD or NSCLC. The direct regulatory association between miR-182-5p and HOXA9 was confirmed by the dual-luciferase reporter assay. Based on these findings, we conclude that miR-182-5p may affect the initiation and development of NSCLC by targeting HOXA9 to diminish the tumor-inhibitory effect of HOXA9 on NSCLC.

Several limitations of this study should be acknowledged. First, we did not validate the oncogenic effect of miR-182-5p on biological events of NSCLC 


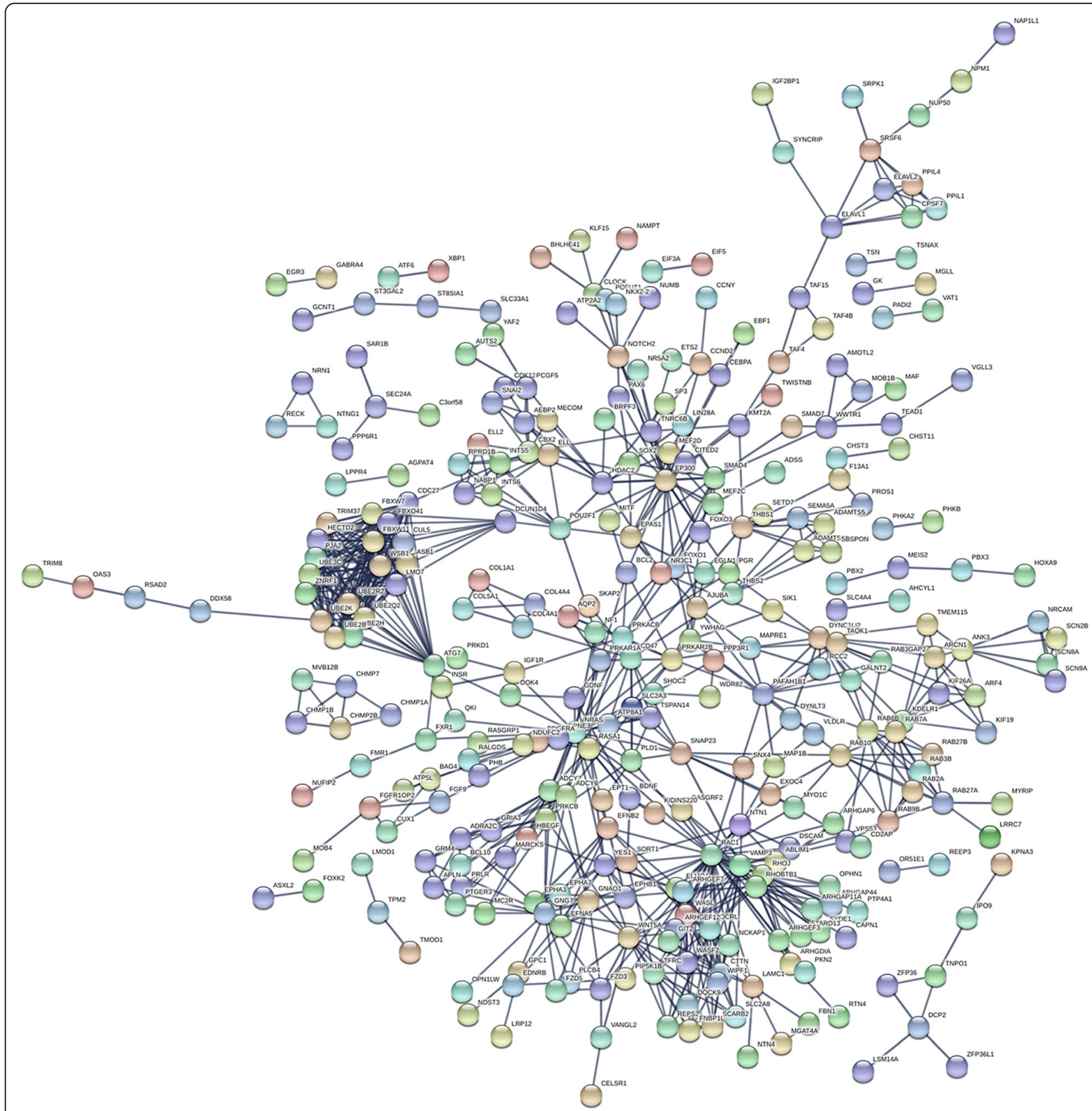

Fig. 9 PPI network for candidate target genes of miR-182-5p. Nodes and strings in the network represented target genes and interactions between target genes

through in vitro or in vivo experiments. Second, this study focused on the clinicopathological significance of miR-182-5p and the miR-182-5p-centered molecular mechanism in NSCLC. Alterations in the expression of various genes, such as EGFR, $A L K$, ROS1, KRAS, and BRAF, play essential roles in NSCLC, and these genes serve as targets of chemotherapy [56]. We did not explore the interactions between miR-182-5p and these genes in NSCLC. Third, the diagnostic value of miR-182-5p in serum was not verified in a large clinical NSCLC sample. Exosomal miRNAs have potential as diagnostic biomarkers for cancers because of their stability, nondegradability, and ease of detection [57]. The diagnostic value of exosomal miR-182-5p in NSCLC was not studied in current work. 


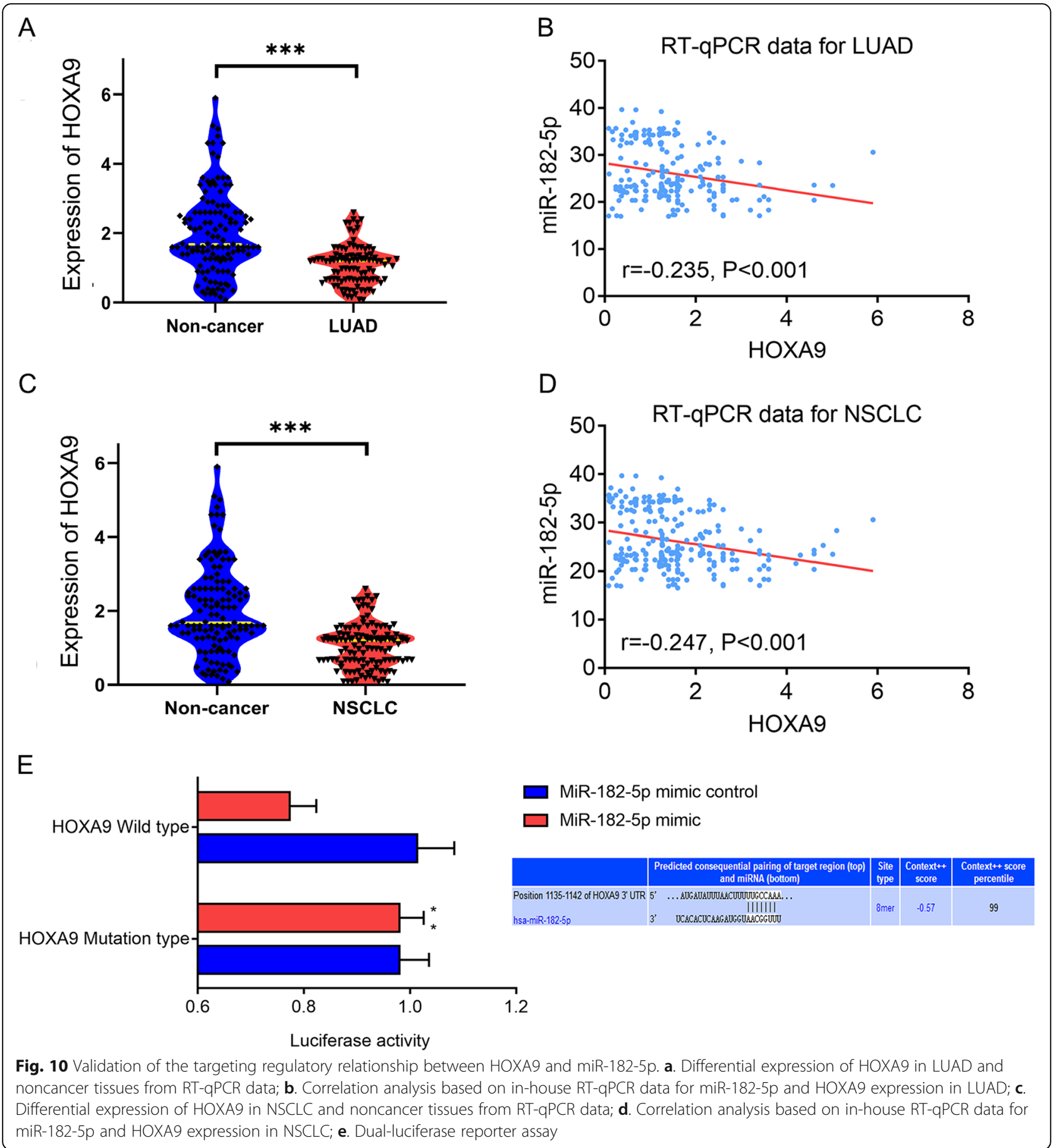

\section{Conclusions}

In conclusion, the oncogenic role of miR-182-5p in NSCLC was confirmed by comprehensively analyzing data obtained from RT-qPCR assays, miRNA-seq and miRNA-chip database. Multiple target genes, including HOXA9, may play a role in the molecular mechanism of HOXA9 in NSCLC.

\section{Supplementary information}

Supplementary information accompanies this paper at https://doi.org/10. 1186/s12920-019-0648-7.

Additional file 1: Figure S1. Differential expression of miR-182-5p in LUAD and noncancer lung tissues based on data from in-house RT-qPCR, miRNA-seq and miRNA-chips. The distribution of miR-182-5p in LUAD and noncancer lung tissues was illustrated in the color of blue and red, 
respectively. A: GSE19945; B: GSE27486; C: GSE29248; D: GSE33045; E: GSE40738; F: GSE47525; G: GSE48414; H: GSE56036; I: GSE93300; J: GSE51853; K: in-house RT-qPCR; L: miRNA-seq

Additional file 2: Figure S2. Differential expression of miR-182-5p in NSCLC and noncancer lung tissues based on data from 9 miRNA-chips, in-house RT-qPCR and miRNA-seq. The distribution of miR-182-5p in NSCLC and noncancer lung tissues was illustrated in the color of blue and red, respectively. A: GSE29248; B: GSE56036; C: GSE93300; D: GSE53882; E: GSE18692-GPL4717; F: GSE18692-GPL4718; G: GSE27705; H: GSE33045; I: GSE36881; J: in-house RT-qPCR; K: miRNA-seq

Additional file 3: Figure S3. ROC curves for distinguishing power of miR-182-5p in LUAD based on data from in-house RT-qPCR, miRNA-seq and miRNA-chips. AUC: area under curves. An AUC value ranging from $0.1-1$ indicated the increasing distinguishing power of miR-182-5p in LUAD. A: GSE19945; B: GSE27486; C: GSE29248; D: GSE33045; E: GSE40738; F: GSE47525; G: GSE48414; H: 51853; I: GSE56036; J: GSE93300; K: miRNAseq; L: in-house RT-qPCR

Additional file 4: Figure S4. ROC curves for distinguishing power of miR-182-5p in NSCLC based on data from 9 miRNA-chips, miRNA-seq and in-house RT-qPCR. AUC: area under curves. An AUC value ranging from $0.1-1$ indicated the increasing distinguishing effect of miR-182-5p in NSCLC. A: GSE56036; B: GSE93300; C: GSE53882; D: GSE18692-GPL4717; E: GSE18692-GPL4718; F: GSE27705; G: GSE33045; H: GSE36881; I: GSE24709; J: miRNA-seq; K: in-house RT-qPCR.

Additional file 5: Figure S5. Differential expression of miR-182-5p in NSCLC and noncancer lung tissues based on data from 16 miRNA-chips. The distribution of miR-182-5p in NSCLC and noncancer lung tissues was illustrated in the color of blue and red, respectively. A: GSE16612; B: GSE17681; C: GSE27486; D: GSE31668; E: GSE40738; F: GSE46729; G: GSE61741; H: GSE19945; I: GSE68951; J: GSE14936; K: GSE15008; L: GSE74190; M: GSE47525; N: GSE48414; O: GSE51853; P: GSE24709.

Additional file 6: Figure S6. ROC curves for distinguishing power of miR-182-5p in NSCLC based on data from 16 miRNA-chips. AUC: area under curves. An AUC value ranging from 0.1-1 indicated the increasing distinguishing effect of miR-182-5p in NSCLC. A: GSE16512; B: GSE17681; C: GSE27486; D: GSE31568; E: GSE40738; F: GSE46729; G: GSE61741; H: GSE68951; I: GSE14936; J: GSE15008; K: GSE19945; L: GSE47525; M: GSE48414; N: GSE51853; O: GSE74190; P: GSE29248.

Additional file 7: Table S1. Predicted target genes of hsa-miR-182-5p from miRWalk database. Putative target genes of hsa-miR-182-5p were predicted by 12 algorithms within mRNA selected regions.

\section{Abbreviations}

AUC: area under the curve; Cl: confidence interval; GEO: Gene Expression Omnibus; GO: Gene Ontology; HOXA9: homeobox A9; KEGG: Kyoto Encyclopedia of Genes and Genomes; miRNA: microRNA; NSCLC: non-small cell lung cancer; PPI: protein-protein interaction; RT-qPCR: real-time quantitative polymerase chain reaction; SMD: standard mean difference; SROC: summary receiver operating characteristic; SROC: summary receiver operating characteristic (SROC); TCGA: The Cancer Genome Atlas

\section{Acknowledgements}

We expressed sincere thanks to the patients included in this study, the target gene prediction tools (miRWalk, Microt4, miRanda, mirbridge, miRDB, miRMap, miRNAMap, Pictar2, PITA, RNA22, RNAhybrid, Targetscan, Tarbase and mirTarbase), and the TCGA, GEO and STRING databases.

\section{Author's contributions}

All authors have contributed to this study for submission. The contributions are as following: LG analyzed all experiment results, prepared for tables and figures, and revised the manuscript. SBY contributed to data analysis and paper writing. JY contributed to the conception, modification of the study and instruction of experiment and revision work. JLK contributed to the conception, modification of the study and instruction of experiment and revision work. KS contributed to the conception and modification of the study, and writing of the paper draft. FCM contributed to the conception and modification of the study, and writing of the paper draft. LZH helped to perform the RT-qPCR and analyze the RT-qPCR data. JL contributed to analyze the target genes by GO, KEGG pathway and PPI network and corrected the paper. SYY analyzed the data from RT-qPCR, GEO and TCGA database and wrote the results. RQH performed RT-qPCR, collected and analyzed the data from TCGA and GEO database and corrected the part of the results. $\mathrm{XHH}$ contributed to the design of the study, guided the study method, and corrected the paper. GC contributed to the design of the study, supervised all experiments and corrected the paper. All authors read and approved the final manuscript.

\section{Funding}

The study was supported by funds from National Natural Science Foundation of China (NSFC81560469, NSFC81360327), Natural Science Foundation of Guangxi, China (2015GXNSFCA139009, 2017GXNSFAA198016), Guangxi Medical University Training Program for Distinguished Young Scholars (2017) and Innovation Project of Guangxi Graduate Education (201710598080), Guangxi Degree and Postgraduate Education Reform and Development Research Projects, China (JGY2019050), Medical Excellence Award Funded by the Creative Research Development Grant from the First Affiliated Hospital of Guangxi Medical University, Science and Technology Innovation Training Program for College Students in the First Clinical Medical College of Guangxi Medical University in 2018. 2019 Guangxi Medical University Education and Teaching Reform Project (2019XJGZ04) and Guangxi Zhuang Autonomous Region Health and Family Planning Commission Self-financed Scientific Research Project (Z20180979). The funding bodies played no role in the design of the study and collection, analysis, and interpretation of data and in writing the manuscript.

\section{Availability of data and materials}

The datasets generated and/or analysed during the current study are available in the TCGA (TCGA-LUAD and TCGA-LUSC) (https://portal.gdc.cancer.gov/), GEO (GSE14936, GSE15008, GSE16512, GSE17681, GSE18692 (GPL4717 and GPL4718), GSE19945, GSE24709, GSE27486, GSE27705, GSE29248, GSE31568, GSE33045, GSE36681, GSE40738, GSE46729, GSE47525, GSE48414, GSE51853, GSE53882, GSE56036, GSE61741, GSE68951, GSE74190 and GSE93300) (https://www.ncbi.nlm.nih.gov/gds/), miRWalk (has-miR-182$5 p$ binding site predictions within 3'-UTR region) (http://zmf.umm.uni-heidelberg.de/apps/zmf/mirwalk2/) and TargetScanHuman (TargetScan_7.2_ENST00000396345.1_predicted_targeting_details) (http://www. targetscan.org/cgi-bin/targetscan/vert_72/view_gene.cgi?rs=ENST000003 96345. 1 \&taxid $=9606 \&$ members $=$ miR-182-5p\&showcnc $=0 \&$ shownc $=0$ \&subset=1). Raw data of predicted target genes of miR-182-5p from miRWalk database was included in Additional file 7.

Ethics approval and consent to participate

The study was approved by the Ethics Committee of the First Affiliated Hospital of Guangxi Medical University. Written informed consent was obtained from all of the patients.

\section{Consent for publication}

Not applicable.

\section{Competing interests}

The authors declare that they have no competing interests.

\section{Author details}

${ }^{1}$ Department of Pathology, the First Affiliated Hospital of Guangxi Medical University, Zhuang Autonomous Region, Nanning 530021, Guangxi, China. ${ }^{2}$ Department of Medical Oncology, the First Affiliated Hospital of Guangxi Medical University, Zhuang Autonomous Region, Nanning 530021, Guangxi, China. ${ }^{3}$ Department of Pharmacology, School of Pharmacy, Guangxi Medical University, Zhuang Autonomous Region, Nanning 530021, Guangxi, China. ${ }^{4}$ Department of Respiratory and Critical Care Medicine, the First Affiliated Hospital of Guangxi Medical University, Zhuang Autonomous Region, Nanning 530021, Guangxi, China. ${ }^{5}$ Department of Medical Oncology, the Second Affiliated Hospital of Guangxi Medical University, Zhuang Autonomous Region, Nanning 530021, Guangxi, China. 
Received: 2 May 2019 Accepted: 19 December 2019 Published online: 06 January 2020

\section{References}

1. DeSantis CE, Lin CC, Mariotto AB, Siegel RL, Stein KD, Kramer JL, Alteri R, Robbins AS, Jemal A. Cancer treatment and survivorship statistics, 2014. CA Cancer J Clin. 2014;64(4):252-71.

2. Bai X, Meng L, Sun H, Li Z, Zhang X, Hua S. MicroRNA-196b inhibits cell growth and metastasis of Lung Cancer cells by targeting Runx2. Cell Physiol Biochem. 2017;43(2):757-67.

3. Yu N, Zhang Q, Liu Q, Yang J, Zhang S. A meta-analysis: microRNAs' prognostic function in patients with nonsmall cell lung cancer. Cancer Med. 2017:6(9):2098-105.

4. Pang L, Han S, Jiao Y, Jiang S, He X, Li P. Bu Fei decoction attenuates the tumor associated macrophage stimulated proliferation, migration, invasion and immunosuppression of non-small cell lung cancer, partially via IL-10 and PD-L1 regulation. Int J Oncol. 2017;51(1):25-38.

5. Li X, Han J, Zhu H, Peng L, Chen Z. MiR181b5p mediates TGFbeta1-induced epithelial-to-mesenchymal transition in non-small cell lung cancer stem-like cells derived from lung adenocarcinoma A549 cells. Int J Oncol. 2017;51(1):158-68.

6. He RQ, Li XJ, Liang L, Xie Y, Luo DZ, Ma J, Peng ZG, Hu XH, Chen G. The suppressive role of miR-542-5p in NSCLC: the evidence from clinical data and in vivo validation using a chick chorioallantoic membrane model. BMC Cancer. 2017;17(1):655.

7. Zhou Q, Song Y, Zhang X, Chen GY, Zhong DS, Yu Z, Yu P, Zhang YP, Chen $J \mathrm{H}, \mathrm{Hu} Y$, et al. A multicenter survey of first-line treatment patterns and gene aberration test status of patients with unresectable stage IIIB/IV nonsquamous non-small cell lung cancer in China (CTONG 1506). BMC Cancer. 2017;17(1):462

8. Kobayashi H, Tomari Y. RISC assembly: coordination between small RNAs and Argonaute proteins. Biochim Biophys Acta. 2016;1859(1):71-81.

9. Goto A, Dobashi Y, Tsubochi H, Maeda D, Ooi A. MicroRNAs associated with increased AKT gene number in human lung carcinoma. Hum Pathol. 2016;56:1-10.

10. Gu S, Lai Y, Chen H, Liu Y, Zhang Z. MiR-155 mediates arsenic trioxide resistance by activating Nrf2 and suppressing apoptosis in lung cancer cells. Sci Rep. 2017;7(1):12155.

11. Yue PY, Ha WY, Lau CC, Cheung FM, Lee AW, Ng WT, Ngan RK, Yau CC, Kwong $\mathrm{DL}$, Lung HL, et al. MicroRNA profiling study reveals miR-150 in association with metastasis in nasopharyngeal carcinoma. Sci Rep. 2017;7(1):12012.

12. Gan CZ, Li G, Luo QS, Li HM. MiR-339-5p downregulation contributes to Taxol resistance in small-cell lung cancer by targeting alpha1,2fucosyltransferase 1. IUBMB Life. 2017;69(11):841-9.

13. Lu C, Shan Z, Hong J, Yang L. MicroRNA-92a promotes epithelialmesenchymal transition through activation of PTEN/PI3K/AKT signaling pathway in non-small cell lung cancer metastasis. Int J Oncol. 2017; 51(1):235-44

14. Zhao C, Lu F, Chen H, Zhao F, Zhu Z, Zhao X, Chen H. Clinical significance of circulating miRNA detection in lung cancer. Med Oncol. 2016;33(5):41.

15. Wu Y, Song Y, Xiong Y, Wang X, Xu K, Han B, Bai Y, Li L, Zhang Y, Zhou L. MicroRNA-21 (Mir-21) promotes cell growth and invasion by repressing tumor suppressor PTEN in colorectal Cancer. Cell Physiol Biochem. 2017; 43(3):945-58.

16. Yang $X$, Bai $F, X u Y$, Chen $Y$, Chen $L$. Intensified Beclin-1 mediated by low expression of Mir-30a-5p promotes Chemoresistance in human small cell Lung Cancer. Cell Physiol Biochem. 2017;43(3):1126-39.

17. Wong P, Hui A, Su J, Yue S, Haibe-Kains B, Gokgoz N, Xu W, Bruce J, Williams J, Catton C, et al. Prognostic microRNAs modulate the RHO adhesion pathway: a potential therapeutic target in undifferentiated pleomorphic sarcomas. Oncotarget. 2015;6(36):39127-39.

18. Gallach S, Jantus-Lewintre E, Calabuig-Farinas S, Montaner D, Alonso S, Sirera R, Blasco A, Uso M, Guijarro R, Martorell M, et al. MicroRNA profiling associated with non-small cell lung cancer: next generation sequencing detection, experimental validation, and prognostic value. Oncotarget. 2017; 8(34):56143-57.

19. Halvorsen AR, Bjaanaes M, LeBlanc M, Holm AM, Bolstad N, Rubio L Penalver JC, Cervera J, Mojarrieta JC, Lopez-Guerrero JA, et al. A unique set of 6 circulating microRNAs for early detection of non-small cell lung cancer. Oncotarget. 2016;7(24):37250-9.

20. Pan F, Mao H, Bu F, Tong X, Li J, Zhang S, Liu X, Wang L, Wu L, Chen R, et al. Sp1-mediated transcriptional activation of miR-205 promotes radioresistance in esophageal squamous cell carcinoma. Oncotarget. 2017; 8(4):5735-52.

21. Wang LJ, Zhang KL, Zhang N, Ma XW, Yan SW, Cao DH, Shi SJ. Serum miR26a as a diagnostic and prognostic biomarker in cholangiocarcinoma. Oncotarget. 2015;6(21):18631-40.

22. Yang $\mathrm{CH}$, Wang $Y$, Sims M, Cai C, He P, Yue J, Cheng J, Boop FA, Pfeffer SR, Pfeffer LM. MiRNA203 suppresses the expression of protumorigenic STAT1 in glioblastoma to inhibit tumorigenesis. Oncotarget. 2016;7(51):84017-29.

23. Zhang B, Zhao R, He Y, Fu X, Fu L, Zhu Z, Fu L, Dong JT. MicroRNA 100 sensitizes luminal a breast cancer cells to paclitaxel treatment in part by targeting mTOR. Oncotarget. 2016;7(5):5702-14.

24. Zhang M, Zhang L, Cui M, Ye W, Zhang P, Zhou S, Wang J. MiR-302b inhibits cancer-related inflammation by targeting ERBB4, IRF2 and CXCR4 in esophageal cancer. Oncotarget. 2017:8(30):49053-63.

25. Li C, Yin Y, Liu X, Xi X, Xue W, Qu Y. Non-small cell lung cancer associated microRNA expression signature: integrated bioinformatics analysis, validation and clinical significance. Oncotarget. 2017:8(15):24564-78.

26. Huang W, Tian Y, Dong S, Cha Y, Li J, Guo X, Yuan X. The long non-coding RNA SNHG3 functions as a competing endogenous RNA to promote malignant development of colorectal cancer. Oncol Rep. 2017;38(3):1402-10.

27. Zhang K, Wang YW, Wang YY, Song Y, Zhu J, Si PC, Ma R. Identification of microRNA biomarkers in the blood of breast cancer patients based on microRNA profiling. Gene. 2017;619:10-20.

28. Sharifi M, Moridnia A. Apoptosis-inducing and antiproliferative effect by inhibition of miR-182-5p through the regulation of CASP9 expression in human breast cancer. Cancer Gene Ther. 2017;24(2):75-82.

29. Wei Y, He R, Wu Y, Gan B, Wu P, Qiu X, Lan A, Chen G, Wang Q, Lin X, et al. Comprehensive investigation of aberrant microRNA profiling in bladder cancer tissues. Tumour Biol. 2016;37(9):12555-69.

30. Li CY, Liang GY, Yao WZ, Sui J, Shen X, Zhang YQ, Peng H, Hong WW, Ye $Y C$, Zhang $Z Y$, et al. Identification and functional characterization of microRNAs reveal a potential role in gastric cancer progression. Clin Transl Oncol. 2017;19(2):162-72.

31. Luo J, Shi K, Yin SY, Tang RX, Chen WJ, Huang LZ, Gan TQ, Cai ZW, Chen G. Clinical value of miR-182-5p in lung squamous cell carcinoma: a study combining data from TCGA, GEO, and RT-qPCR validation. World J Surg Oncol. 2018;16(1):76

32. Chen $G$, Kronenberger P, Teugels E, De Greve J. Influence of RT-qPCR primer position on EGFR interference efficacy in lung cancer cells. Biol Proced Online. 2010;13:1.

33. Chen G, Kronenberger P, Umelo IA, Teugels E, De Greve J. Quantification of epidermal growth factor receptor T790M mutant transcripts in lung cancer cells by real-time reverse transcriptase-quantitative polymerase chain reaction. Anal Biochem. 2010;398(2):266-8.

34. Chen G, Umelo IA, Lv S, Teugels E, Fostier K, Kronenberger P, Dewaele A Sadones J, Geers C, De Greve J. MiR-146a inhibits cell growth, cell migration and induces apoptosis in non-small cell lung cancer cells. PLoS One. 2013;8(3):e60317.

35. Lee YS, Kim H, Kim HW, Lee JC, Paik KH, Kang J, Kim J, Yoon YS, Han HS, Sohn I, et al. High expression of MicroRNA-196a indicates poor prognosis in resected pancreatic neuroendocrine tumor. Medicine. 2015;94(50):e2224

36. Tang R, Zhong T, Dang Y, Zhang X, Li P, Chen G. Association between downexpression of MiR-203 and poor prognosis in non-small cell lung cancer patients. Clin Transl Oncol. 2016;18(4):360-8.

37. Chen WJ, Gan TQ, Qin H, Huang SN, Yang LH, Fang YY, Li ZY, Pan LJ, Chen G. Implication of downregulation and prospective pathway signaling of microRNA-375 in lung squamous cell carcinoma. Pathol Res Pract. 2017; 213(4):364-72.

38. He R, Yang L, Lin X, Chen X, Lin X, Wei F, Liang X, Luo Y, Wu Y, Gan T, et al. MiR-30a-5p suppresses cell growth and enhances apoptosis of hepatocellular carcinoma cells via targeting AEG-1. Int J Clin Exp Pathol. 2015;8(12):15632-41.

39. He RQ, Gao L, Ma J, Li ZY, Hu XH, Chen G. Oncogenic role of miR1835p in lung adenocarcinoma: a comprehensive study of $\mathrm{qPCR}$, in vitro experiments and bioinformatic analysis. Oncol Rep. 2018;40(1):83-100.

40. Gao L, He RQ, Wu HY, Zhang TT, Liang HW, Ye ZH, Li ZY, Xie TT, Shi Q, Ma J, et al. Expression signature and role of miR-30d-5p in non-small cell Lung Cancer: a comprehensive study based on in Silico analysis of public databases and in vitro experiments. Cell Physiol Biochem. 2018:50(5):1964-87.

41. Gao L, Li SH, Tian YX, Zhu QQ, Chen G, Pang YY, Hu XH. Role of downregulated miR-133a-3p expression in bladder cancer: a bioinformatics study. Oncol Targets Ther. 2017;10:3667-83. 
42. Zhang XL, He RQ, He QC, Dang YW, Chen G. Expression of HOXA9 mRNA in non-small cell lung cancer and their clinical significance. Chin J Diagn Pathol. 2015; http://kns.cnki.net/kcms/detail/detail.aspx?FileName=ZDBL2015 09003\&DbName=CJFQ2015.

43. Gao X, WU Y, Yu W, Li H. Identification of a seven-miRNA signature as prognostic biomarker for lung squamous cell carcinoma. Oncotarget. 2016; 7(49):81670-9.

44. Ma Y, Liang AJ, Fan YP, Huang YR, Zhao XM, Sun Y, Chen XF. Dysregulation and functional roles of miR-183-96-182 cluster in cancer cell proliferation, invasion and metastasis. Oncotarget. 2016;7(27):42805-25.

45. Xie K, Wang C, Qin N, Yang J, Zhu M, Dai J, Jin G, Shen H, Ma H, Hu Z. Genetic variants in regulatory regions of microRNAs are associated with lung cancer risk. Oncotarget. 2016;7(30):47966-74.

46. Wei Q, Lei R, Hu G. Roles of miR-182 in sensory organ development and cancer. Thorac Cancer. 2015;6(1):2-9.

47. Wang F, Zhong S, Zhang H, Zhang W, Zhang H, Wu X, Chen B. Prognostic value of MicroRNA-182 in cancers: a meta-analysis. Dis Markers. 2015;2015:482146.

48. Dejima $H$, linuma $H$, Kanaoka R, Matsutani N, Kawamura M. Exosomal microRNA in plasma as a non-invasive biomarker for the recurrence of nonsmall cell lung cancer. Oncol Lett. 2017;13(3):1256-63.

49. Li Y, Zhang H, Gong H, Yuan Y, Li Y, Wang C, Li W, Zhang Z, Liu M. Liu H, et al. J Exp Clin Cancer Res. 2018;37(1):141

50. Chang H, Liu YH, Wang LL, Wang J, Zhao ZH, Qu JF, Wang SF. MiR-182 promotes cell proliferation by suppressing FBXW7 and FBXW11 in non-small cell lung cancer. Am J Transl Res. 2018;10(4):1131-42.

51. Zhu W, Zhou K, Zha Y, Chen D, He J, Ma H, Liu X, Le H, Zhang Y. Diagnostic value of serum miR-182, miR-183, miR-210, and miR-126 levels in patients with early-stage non-small cell Lung Cancer. PLoS One. 2016;11(4):e0153046.

52. Ning FL, Wang F, Li ML, Yu ZS, Hao YZ, Chen SS. MicroRNA-182 modulates chemosensitivity of human non-small cell lung cancer to cisplatin by targeting PDCD4. Diagn Pathol. 2014;9:143.

53. Bhatlekar S, Fields JZ, Boman BM. HOX genes and their role in the development of human cancers. J Mol Med (Berl). 2014;92(8):811-23.

54. Gilbert PM, Mouw JK, Unger MA, Lakins JN, Gbegnon MK, Clemmer VB, Benezra M, Licht JD, Boudreau NJ, Tsai KK, et al. HOXA9 regulates BRCA1 expression to modulate human breast tumor phenotype. J Clin Invest. 2010; 120(5):1535-50.

55. Son JW, Jeong K, Jean WS, Park SY, Jheon S, Cho HM, Park CG, Lee HY, Kang J. Genome-wide combination profiling of DNA copy number and methylation for deciphering biomarkers in non-small cell lung cancer patients. Cancer Lett. 2011;311(1):29-37.

56. Zhuang X, Zhao C, Li J, Su C, Chen X, Ren S, Li X, Zhou C. Clinical features and therapeutic options in non-small cell lung cancer patients with concomitant mutations of EGFR, ALK, ROS1. KRAS BRAF Cancer Med. 2019 https://doi.org/10.1002/cam4.2183.

57. Taylor DD, Gercel TC. MicroRNA signatures of tumor-derived exosomes as diagnostic biomarkers of ovarian cancer. Gynecol Oncol. 2008;110(1):13-21.

\section{Publisher's Note}

Springer Nature remains neutral with regard to jurisdictional claims in published maps and institutional affiliations.

Ready to submit your research? Choose BMC and benefit from:
- fast, convenient online submission
- thorough peer review by experienced researchers in your field
- rapid publication on acceptance
- support for research data, including large and complex data types
- gold Open Access which fosters wider collaboration and increased citations
- maximum visibility for your research: over 100M website views per year
At BMC, research is always in progress.
Learn more biomedcentral.com/submissions

